\title{
Doctoral Dissertations in Geography Accepted at Japanese Universities, Academic Year 2005
}

\begin{abstract}
ABE Ryogo: Ethnicity and Urban Space in Japan: Differences and Spaces over Filipino Female Entertainers. Nagoya University, March 2006.
\end{abstract}

Female migrants from the Philippine have been a symbolic existence of the "feminization of migration" since 1970s. Most of them are domestic workers or nurses leaving for the Western countries, Middle East and South Eastern Asia. The others are Entertainers to Japan since 1980s, which are dancers or singers. The former mainly work at domestic spaces or in the hospital around the world, and the latter, which is the focus of my thesis, usually work at so-called "Philippine Pub" in the urban nightscapes all over Japan. The purpose of my thesis is to disclose the politics of differences and spaces over the Filipino female entertainers.

To explore my purpose, I adopted two perspectives. The first is social constructionism of ethnicity. Social constructionism regards a category as a social construct, rather than as natural or essential. All differences, for example gender, class, sexuality and so on, are socially constructed through categories. Then according to social constructionism, we can change those differences if a category is not natural or essential but just a construct. Ethnicity is one of differences and also a social construct. Thus, the question is which ethnicity is socially constructed by, and how? We must examine the processes of ethnicitization, racialization and differentiation in detail.

The second perspective is the spatialization of differences. Generally speaking in geography, spaces are differentiated. But I would like to argue that differences are also spatialized. Differences as constructs are (re)produced through spaces formed socially. Thus, social construction of ethnicity is not separated with the formation of spaces. So, the question is which spaces are formed by, and how?

My study area is in Nagoya City, Aichi Prefecture, Japan. It is famous for agglomeration of the Philippine Pubs, being equal with Tokyo. Espe- cially, "Sakae Walk Streets" in Naka Ward of Nagoya City is the heart of location of Philippine Pubs. In this area, there have been a lot of Philippine Pubs since the middle of 1980s.

Under two perspectives above, I explored the politics of differences and spaces over Filipino female entertainers in Sakae Walk Streets, through two case studies.

In the first case study, I focused on the social construction of ethnicity and the formation of spaces of Philippines Pubs at local scale. Then I identified two groups around entertainers. One is the pub business group such as owners, and the other is the pubic authorities such as the immigration bureau and police. The former formed a Pub space as amusement through constructing ethnicity as sex, exotic and the nature of southern country. On the other hand, the latter formed a Pub space as policing through constructing ethnicity as criminals or victims. In my conclusion, Spaces of Philippines Pubs work as othering Filipino female entertainers out of Japanese society, whether amusement or policing.

In the second case study, I focused on the micro scale geographies of a Philippine Pub in Sakae Walk Streets, paying attention to performances of entertainers. The purpose of this case study is to clarify what kind of performances both pub owners and pub customers expect of entertainers. Pub owners control the everyday space of entertainers both at work and at residence through expecting hostess performance of them rather than entertainment performance. On the other hand, Pub customers gaze at entertainers within a Pub through expecting performances of them as emotional, hospitality, pure and the nature of old Japanese mind. I would like to point out that the gaze includes Japanized Orientarism. In my conclusion, Japanese society situates Filipino female entertainers as other at micro scale geographies with the politics of ethnicity and spaces.

I was able to disclose the politics of differences and spaces over Filipino female entertain- 
ers in Japan. In addition, I think I could contribute to ethnic studies in Japanese geography by social constructionism of ethnicity and the spatialization of differences. So this is the final question. Can the existence of Filipino female entertainers lead Japanese society to diversification of ethnicity? Does a new view of Japan come? It's a difficult question to answer in my thesis. Social construction of ethnicity is not limited to Filipino female entertainers. I have to take a social construction of Japanese into the question in my future study.

\section{ARAI Tomokazu: "The Politics of Place" on the Yokota Air Force Base in Fussa City. Tokyo Metropolitan University, March 2006.}

Military bases are generally established for global geopolitical purposes. However, the establishment of a military base has cultural implications for the local communities where the base is located, i.e., increased concerns about crimes committed by servicepersons and noise by aircrafts. Although these military bases have some serious impacts, especially in Japan, geographers have not yet examined the issues regarding a particular military base and the resultant politics in the city.

On the contrary, since the 1980s, Anglo-American political geographers have paid more attention to "the politics of place." This refers to the local politics that occur due to the interaction between a structural constraint and the individuality of a particular place.

Therefore, this study examines the interaction between the politics in Fussa City and the Yokota Air Force Base, that is "the politics of place" from a range of political, economic, and cultural processes which maintain the existence of the base by using resources from local newspapers, novels, magazine articles, and council proceedings.

The results are as follows. Owing to the interdependence between the U.S. Air Force and local, political and economic agents, an urban structure and local economy that depended on the Yokota Air Force Base were constructed in Fussa Town after the establishment of the base in 1945. Because of this structure, the local economy became to depend on air force personnel as consumers. However, due to a shift from the floating exchanging rate and a reduction in the population of the base in the first half of the 1970s, there was a decrease in the influence that air force personnel had on the local economy. Since the 1980s, an economic agent utilized the "atmosphere" and "image" adjacent to the base to revitalize the local economy. Furthermore, the mass media represented Fussa City as a "base town" and conducted a review of the city in the 1960 s, thus contributing to its revitalization. During the economic slump in the 1970s, some local political agents were against the existence of the base. However, successive mayors of Fussa City have accepted the existence of the base, and utilized the subsidies it receives from the national government in order to construct the urban infrastructure.

\section{FuLin DU: The Research of Sustainable Animal Husbandry in Inner Mongolia of China. Okayama University, September 2005.}

The study mainly researches the typical grasslands of animal husbandry region and the halfagricultural and the half-husbandry region in Inner Mongolia. The starting point is the farmhouse management and the grasslands utilization, after that clarify their current state. In addition trying to find the effective ecology protecting policy which is executed by the country and the province which on the sustainable development of the regional agriculture. And to know how the policy affects farmhouse management and how the peasant evaluates it

In chapter 1 , through using general data and materials about animal husbandry in Inner Mongolia, the author examined the current state of the developing nation husbandry; the transition of the animal husbandry form and the problem in the grassland utilization.

In chapter 2, the study clarified: the management of the cattle-breeding farmhouse, the present state of the form of utilizing form in the grassland cattle-breeding region. The farmers intend to take a balance between domestic animal and grass by grass sampling ground, feed ground, grassland borrowing from the farmhouse in the other area etc, but many farmhouses have not escaped from the condition of excessive grazing. The large-scale management depends on the leased land mainly. However, to make a load to 
the leased land weight to try to use its unit contract green, being rational as much as possible, being continuous and being efficient is occurring too. And, renting of the grassland jumped by the run recent years and the situation that a lender isn't readily found.

The rotation grazing attracts out attention. In general, extensive grassland and investment are necessary for rotation grazing. The farmhouse with the narrow grasslands cooperates to carry out rotation grazing. They are attempting to get a stable income. It is important meaning for the farmhouse with grasslands which often exist in the animal husbandry area.

In chapter 3 , the author clarified the current state of the farming management of the farmer in the half-agricultural and the half-husbandry region. The farmhouse management income is fundamentally constituted by animal husbandry. The domestic animal income is chiefly composed of the domestic animal sales income and the cashmere income. The dependence to the sale income changes with the scale management most of the farmhouse utilize carelessly without taking measure of protection and management for the contract grassland. Even competition and plunder is used for the common grassland.

In chapter 4 , the influences in the living and agriculture production to farmer and farmer's intention in Inner Mongolia and the farmer's assessment of the policy which is called replacing agriculture by afforestation are clarified. The influence of the policy is shown in the ecology renewed effects, the changes of the plant structure, the development of the animal husbandry, the income of the herdsman and the decrease of the labor force etc.

In conclusion, through strengthening the way of the utilization of the grasslands or improve the husbandry to solve the impoverished problem, the future question for study is making sure the stability and long term of the policy of replacing agriculture by afforestation and the policy of replacing animal husbandry by grass.

\section{Raelyn Lolohea 'ESAU: International Migration by Tongans and Their Experiences in Host Countries: Cases in New Zealand, Fiji and Japan. Kyoto University, March 2005.}

This dissertation investigated international mi- gration from Tonga and the experience of Tongans based on case studies in New Zealand, Fiji, and Japan. The purpose of the study in Tonga is to examine the socio-cultural aspects of international migration from Tonga and its impact based on a behavior approach, which has thus far been neglected in existing literature on Tonga. The following findings were obtained. Household size has recently decreased due to the transformation from extended to nuclear families and emigration from Tonga. Now the individual or nuclear family plays a greater role in migration decision making than the extended family. Since the 1990's the increasing motivation to migrate to study abroad is remarkable.

The New Zealand case study sought to shed light on the experiences of Tongans by exploring three major areas: the migration decision making process, socio-economic changes in the host country, and transnational networks with Tonga. The nuclear family plays an important role as the final decision making unit. Family-related reasons, jobs, and study were the typical reasons for migration to New Zealand. Regarding socioeconomic changes, immigrants' income tends to increase as their duration of stay in New Zealand lengthens. Most have blue collar jobs. Unmarried at migration, many immigrants married after moving to New Zealand, mostly to other Tongans. The church serves as a critical support system for immigrants. Tongans tend to prefer permanent residence visas over New Zealand citizenship. Despite these continuing links with their home country, most immigrants do not wish to permanently return to Tonga.

The case study in Fiji examined the migration experiences of Tongan students and households. Student survey results elucidated that the decision to migrate for college was made on an individual basis, while the role of family and friends in disseminating information about institutions was conspicuous. University destination was influenced by the availability of scholarships for studying in Fiji. The majority of students expect to return to Tonga to resume or find employment after completing their studies. Household survey findings confirm the important role of the nuclear family in decision making and reasons for migration while employers funded the migration expenses for most individuals. The 
highest university degrees have been acquired since the 1990s, mainly from Fiji and Australian universities. Many are involved in such skilled occupations as education and administration at major South Pacific regional organizations, reflecting their higher educational attainment.

The case study in Japan concentrated on three main groups of immigrants: spouses of Japanese nationals, rugby players, and tertiary students. Clearly such factors as marriage, playing rugby, and acquiring an education are the main reasons for immigration. As for the spouses of Japanese nationals, the longer their period of residence in Japan, the greater is their tendency to change their legal status and they are highly unlikely to return to Tonga. While the contract duration of migrants who play rugby is limited by age and physical strength, some opt to stay in Japan, especially those who initially migrated on rugby scholarships. However, the majority of such athletes and college students do wish to return to Tonga permanently when their visas expire.

\section{HASHIMURA Osamu: A Study of Historical Geography Focussed on Possession of the Sea and Use of the Resources of the Sea Fishery. Kokugakuin University, March 2006.}

This thesis is a work of historical geography focused on possession and re-organization of fishery grounds as well as the use of their resources in Kyushu from the $15^{\text {th }}$ to the $19^{\text {th }}$ century.

Fishery right in Japan is generally regarded as resources management system based on a village unit. However, there also existed private fishery right which did not belong to the villages. We need to find out the formation process of such fishery rights from the angle of historical geography. In this thesis I take up the cases in western Kyushu along Japan Archipelago.

The conclusion of the study is as follows. In Goto chain islands in western Kyushu, possession or using right under rotation system of AJIRO (favorite haunts of fishes) was formed in the $14^{\text {th }}$ century. As time descended, in early modern times these privileges were succeeded as private rights in the names of KATOKU or Oshikiami (triangular set net). On the other hand, division of fishing area was initially introduced in the late $14^{\text {th }}$ century, and afterwards established as fishing grounds owned by Urakata (fishing village) in Higo-Amakusa District in western Kyushu. In the late $18^{\text {th }}$ century, the fishing grounds owned by Urakata were subdivided, through which the adjacent sea in front of one village (JISAKI) was widely established. In the off-shore fishery front which was developed rapidly in the late $17^{\text {th }}$ century, exclusive rights on fishing grounds or fish reef were established in the late $18^{\text {th }}$ century through the $19^{\text {th }}$ century.

As mentioned above, from the $13^{\text {th }}$ century on, fishery grounds were expanded from a point to surface which means from the adjacent sea in front of one village to the offshore sea. In actual condition of the fishery grounds, the distinction between the adjacent sea in front of the village and the offshore was never clear. Further, even within exclusive fishery grounds, private AJIRO was permitted to particular individuals with priority right.

It was confirmed that the title structure was not singular but multilateral. In other words, this is a specific characteristic of the mode of the possession of the sea surface, which means that the titles were multilaterally fixed for the same sea area. It has to do with the substance of fishing industry which always aims at the Moving Resources depending on the season of the year and the depth of the sea.

In south-western Kyushu, in early modern times, the stage of major fishing industry had shifted from the village sea area to the migratory fish abundant open seas. The various pattern of fishing rights developed after the mid $18^{\text {th }}$ century in Kyushu area has a distinct contrast to that of inner-sea area like Seto Naikai. This will become a model of the development history of fishing industry in Japan.

\section{KATAOKA Hiromi: Study on the Establishment and Development of Brazilian Ethnic Businesses and their Relation to the Regional Community. Nagoya University, March 2006.}

This study pointed out the necessity of giving attention to economic side of ethnicity rather than emphasizing on residential aspects as traditional geography. Although the number of recent ethnic geographic study is increasing, they are macro scale researches where ethnicity or 
the accepting community around it seems to be treated as a whole, or to be considered to have the same characteristics. That is why this study also suggested the significance of micro scale analysis.

I examined one of the economic phenomena "ethnic businesses" which are accompanied with ethnicity from mezzo and micro scale point of view and chose Hamamatsu city, Shizuoka prefecture as a subject region, because it has more Brazilians who have registered as alien residents than any other municipalities in Japan. And also because the numbers of Brazilians are dramatically increasing there, since amendments to the immigration law in 1990 was enforced. This study suggested formation and development of ethnic businesses, and their meanings to Brazilians, and their effects on accepting community including citizens of the society.

In the first case study, chapter III, I analyzed the formation, background, present conditions of ethnic businesses, development in the local society, and examined their role and meanings by questionnaires and conversations with Brazilians on ethnic businesses in Hamamatsu city. Since amendments to the immigration law in 1990 , Hamamatsu City and areas around Hamamatsu City have experienced an increase in the number of residents of Brazilian nationality. This has in turn expanded the trade area of many ethnic business offices, and subsequently created an increase in "delocalized-customer-base-ethnicmodel" businesses targeting Brazilians residing in surroundings areas of Hamamatsu City; "external-market-expanding-model" businesses that also target non-Brazilian customers. There is marked trend of an increase in the number of businesses adopting a route of business activity involving project development covering a wide spectrum of areas, and the advancement into external markets, namely targeting non-Brazilian customers. It is therefore predicted that there will be continued growth of these businesses from hereon. And in this chapter, I clarified that there existed alternative ethnic businesses by Japanese in accepting community.

The second case study, chapter IV, I exposed the nature of the ethnic solidarity of Brazilian residents in Hamamatsu City, Shizuoka Prefecture, through research and analysis of the con- sciousness and state of usage of ethnic businesses by Brazilian residents. Apart from being places that provide goods or services, ethnic businesses also serve to perform social and cultural functions; which to many Brazilian residents makes these businesses "special places". The development of the functions performed by these ethnic businesses is closely connected to the characteristic form of international migration, adopted by the Brazilians who flooded into Japan following an amendment to immigration law; in particular the "market intervention form of migration" and the "refluxing model of migration". In Hamamatsu, a city with relatively little ethnic solidarity, ethnic communities are gradually forming, with ethnic businesses possessing the above-mentioned social and cultural functions, at the heart of this formation. These communities that are forming can be characterized as being open and flexible. And I paid attention to not only from the mezzo scale research of ethnic businesses as in the relationship with ethnic groups which has not been studied much in traditional geography, but also to the consciousness of each member of the ethnic groups and clarified the difference of their awareness regarding ethnicity by micro scale analysis.

The third case study, chapter V, analyzed the relationship between ethnicity and the accepting community, not from macro scale examination as the regular study, but from micro scale research by investigating the connection between the ethnic businesses and the citizens of accepting community.

In general, ethnicity tends to have a possibility of forming discrimination and alienation. $\mathrm{Al}$ though numbers of Brazilian permanent residents in Japan are increasing, there are few opportunities to have communications and cultural exchanges with local Japanese citizens. And intensification of media coverage of crimes by foreigners makes the Japanese local residents becoming anxious on the increase of foreigners in the community. So in Hamamatsu city, there is a possibility of serious conflicts between Brazilian residents and Japanese citizens from the above said background. However, Brazilian stores in Hamamatsu city, which are the center of Brazilian community, are not for Brazilian residents only, but they have a function as "Contact zone" 
where cultures and lives of two countries meet. And they have a significant role for both nationals in having exchange and contact with each other, and creating "Hybrid-culture". And they also have become impelling force for activation of local society. And it is necessary to utilize the Brazilian businesses fully for their various effects as important resources to create coexisting society of Brazilians and Japanese.

\section{KAWAKUBO Atsushi: Changes and Reorganization of Japanese Citrus Fruit Producing Areas after World War II. Hiroshima University, July 2005.}

In this paper, I focus on the postwar development and changes (growth diversification and decline) of Japanese agriculture from a geographical perspective and try to elucidate the factors involved. Specifically, as a representative agricultural product, I focus on citrus fruit for two reasons: it exhibits production trends, a spectrum of production areas, changes in agricultural policies, trends of trade, etc, typical of Japanese agriculture after World War II; it can also demonstrate today's agricultural problems in Japan.

In my analysis, I concentrate on following three points. The first point is how reactions of citrus fruit producing areas (CFPAs) to changes in market condition varied with geographical region. The second point is how reactions of CFPAs to changes in agricultural policies varied with geographical region. The third point concerns the different types of CFPAs. I categorized all of the CFPAs, based on their cultivated citrus varieties and I recognized five types of CFPAs (traditional, newly established, miscellaneous, greenhouse, for the processing industry).

As a result, I elucidated the model of geographical variations in the CFPAs' changes after World War II. As explained in detail below, the CFPAs changed chiefly in response to an Agricultural Basic Law (1961), the sudden drop in the prices of the Satsuma orange (1972), and the lifting of the orange importation restrictions (1988).

The "traditional" Satsuma orange producing areas (SOPAs) established before 1960 developed well following the increase in demand and the introduction of the government's agricultural policies. From 1972, they began to shrink and reorganize until around 1980, forming different categories of CFPAs because of the fall in the demand for Satsuma oranges. Some started specializing in reputable miscellaneous oranges, or Satsuma oranges destined for the processing industry and, in the late 1970 s, some began specializing in greenhouse Satsuma oranges. But traditional SOPAs almost continue to prosper.

On the other hand, most of the SOPAs that were newly established in between 1960 and 1970 with the backing of the government or other help went into steep decline in the late $70 \mathrm{~s}$ because they did not turn to cultivating other products. Some continued as SOPAs, and successfully turned to producing greenhouse Satsuma oranges, but most of them declined much further in the beginning of the $90 \mathrm{~s}$ because the workers became old, which resulted in a lack of labor.

Compared to the SOPAs, the miscellaneous oranges producing areas did not undergo much change. The proportion that continued to prosper was high. Some of the traditional miscellaneous orange producing areas turned to cultivating Satsuma oranges whose demand suddenly grew between 1950 to 1960, and some switched over to Satsuma oranges, but most just continued as miscellaneous oranges producing areas.

From the above analysis I can make the following conclusions concerning the factors in the regional variations of the changes and reorganizations of the CFPAs.

First, there were two conditions, which varied between regions, that allowed SOPAs to prosper as before: natural conditions that favored cultivations of good quality produce; and a history of know-how necessary for high-level production and good sales. SOPAs that were disadvantaged in natural and social factors such as climate, soil, cultivation skills, reputation, and marketing had to either suffer a decline or start producing another product. Newly established SOPAs are one of them.

However, leaders of the CFPAs organization and pioneers with initiative bear a large responsibility for restricting SOPAs from changing into other types of CFPAs. For example, they were responsible for decisions concerning changing the type of Satsuma orange or the timing in 
adopting certain facilities, the choice of switching to miscellaneous oranges or other fruit. Of course the natural conditions and other conditions at the time would have affected the outcomes of the decisions, but the wrong decisions would certainly have resulted in a state of decline. However, only the greenhouse CFPAs were able to overcome poor natural conditions, and since none had a history of using green houses, by moving turning to greenhouse Satsuma oranges, almost all CFPAs in Japan had a chance to succeed.

\section{KAWASUMI Takaaki: Late Quaternary Glacial Chronology, Equilibrium-line Altitudes and Influence of Volcanic Events on Glaciers on Mt. Tateyama, Hida Range, Central Japan. Tokyo Metropolitan University, September 2005.}

Five glacial stades (Murodo Stade I: just before 70 ka, Murodo Stade II: just after 70 ka, Tateyama Stade I: just before 29 cal ka, Tateyama Stade II: 18-20 ${ }^{10} \mathrm{Be} \mathrm{ka}$ and Tateyama Stade III: $10-11$ $\left.{ }^{10} \mathrm{Be} \mathrm{ka}\right)$ on Mt. Tateyama $(3,015 \mathrm{~m})$ and the Tateyama Volcano $(2,670 \mathrm{~m})$ in Hida Range in central Japan during the last glacial period are recognized on the basis of glacial sediments, moraines and their stratigraphic relationships with volcanic ejecta.

On Mt. Tateyama comprising granitic bedrock, the glaciers mainly reacted to the climatic conditions, becoming less extensive with time. On the eastern (downwind) slopes of Mt. Tateyama, one of them developed into a valley glacier with $6 \mathrm{~km}$ long and 1,660 m vertical distance between the highest and lowest glacier limits in Murodo Stade I and reached the bottom $(1,200 \mathrm{~m})$ of the Kurobe Gorge that is the deepest gorge in Japan. The glaciers on Mt. Tateyama were forcibly melted and reduced between Murodo Stades I and II by the fall of pumices ( $c a .70 \mathrm{ka}$ ) erupted from the Tateyama Volcano, and readvanced in Murodo Stade II after the pumice fall had finished. The maximum glacial expansions during the last glacial period simultaneously occurred just before the fall of pumices ( $c a .70 \mathrm{ka}$ ) in MIS 4 on the high mountains in the Hida Range. The maximum glacial advances during the late stade also simultaneously occurred just before $29 \mathrm{cal} \mathrm{ka}$ in MIS 3 on the high mountains in the Hida
Range. The glacial equilibrium-line altitudes (ELAs) lay at $1,868 \mathrm{~m}, 2,138 \mathrm{~m}, 2,305 \mathrm{~m}, 2,550$ $2,605 \mathrm{~m}$ and $2,635 \mathrm{~m}$ in order of stades. The maximum ELA depression reached about $1700 \mathrm{~m}$ compared to the modern ELA ( $c a .3,600 \mathrm{~m}$ ).

In contrast, the glaciers on the Tateyama Volcano became more expansive with time from Murodo Stades I and II through Tateyama Stade I, because the successive appearances of lava peaks had progressively widened the accumulation area on the summit region of the volcano. However, it has not been confirmed whether the glacier snout descended most in Tateyama Stade I. During Tateyama Stade I, the repeated collapse of caldera walls narrowed the accumulation area, so that the glaciers intermittently decreased in size on the volcano. In Tateyama Stades II and III, the Tateyama Volcano barely changed its size and height, and the glaciers on the volcano retreated with time depending on the climatic conditions.

In Tateyama Stade I, a chain of the glacial events was caused on Mt. Tateyama. The glaciers of the Tateyama Volcano became the most expansive in Tateyama Stade I, and a large quantity of glacier ice flowed from the Tateyama Volcano into the head of the south-facing glacial valley on Mt. Tateyama immediately outside the volcano. The result was that the large-scale glacier appeared in the south-facing glacial valley, which is generally unsuitable for glaciations in the Northern Hemisphere due to the receiving great solar radiation. The large inflow of the glacier ice caused intensive headward erosion in the southfacing glacial valley. The valley head retreated northwards and captured a part of glacier belonging to the north-facing glacial valley on Mt. Tateyama. The glacier of the north-facing glacial valley reduced and shifted its snout and fluvioglacial channel westwards. The fluvioglacial flows eroded and isolated the Murodo Stade glacial sediments as a moraine-like slender ridge between two parallel fluvioglacial channels in Tateyama Stade I.

KOHARA Takeaki: Development and Significance of Urban Redevelopments: The Cases of Osaka. Kyoto University, March 2006.

I am concerned with the spatial and social as- 
pects of urban redevelopments. The purpose of this study is to examine how urban redevelopments come into being, and to clarify their significance. This study consists of seven chapters as follows.

In chapter one, I review the previous studies about urban redevelopments from the viewpoint of their history after World War II and the 'actors' concerned in them. I point out the shortage of multi-angle studies about urban redevelopments.

I attempt to classify the urban redevelopments by their beginnings, the reasons for their existence and their problems in the second chapter.

The third chapter analyzes the spatial changes in the area around JR Osaka Station by using grid data of floor use. As a result of this analysis, I can clarify that the changes after the bubble economy burst resulted from the urban redevelopments in the area. I also indicate that the urban redevelopments did not influence the surrounding areas.

In chapter four, I point out the change in structure of land-ownership, from individualbased to one based on corporations, in the area around JR Osaka Station after World War II. I also point out the acquisition process of lots by the Hankyu Corporation Group. The group bought many lots within the area in order to enforce urban redevelopments.

The fifth chapter examines the development of real estate businesses by the Hankyu Corporation Group. I prove that the group established the foundation of its real estate leasing among the period of high economic growth through its redevelopments in the Umeda area of Osaka City and that the management of the group has been supported as a result of the redevelopments.

The social significance of the urban redevelopments in the Ueroku area of Osaka City, is considered in the sixth chapter. The urban redevelopment was conducted by the residents, who started to live there after the Pacific War and had not had land-ownership at that time. For the residents, the significance of the urban redevelopment was to achieve a greater level of social stability as a result of acquiring land-ownership and to be recognized as rightful occupants by the Osaka City government and the public.

In the last chapter, I point out a few opinions about the developments and the significance of urban redevelopments. I also suggest that we need to grasp their significance, comprehensively, not by generalizing them but by considering many various cases.

\section{Yungang LIU: The Change of the Industrial Structure and Human Activity Spaces in Chinese Mining Cities. The University of Tokyo, March 2006.}

Since 1950s, many mining cities have emerged from large-scale resource development during the process of modern industrialization in China. The cities are holding a balance role in Chinese economic and social development as an important component of urban system. However, for many years, little research achievement has been made on them. On one hand it is due to the little attention paid, on the other hand it was difficult to access to the mining cities for physical and factitious reasons because of limitation to available exoteric information of Chinese mining cities. Thanks to the Opening and Reformation policy, the opportunity to study mining cities comes.

This thesis investigates the change in the industrial structure and human activity spaces in Chinese mining cities since 1950s. Utilizing the existing literature which includes chorography, statistical and map datum, the author firstly identifies the category of Chinese mining cities and its distribution characteristics. And then the author choose Liaoyuan city, a colliery city located in Northeast of China, as a fieldwork case to investigate the Chinese mining cities.

This thesis consists of three parts. The first part synthetically analyzes the general developing history, recent status and trends of the Chinese mining cities. In this part, a definition of mining cities based on the principle of "forming for mining" is proposed. According to the definition, 58 of 667 organizational cities are identified as mining cities. Because of the limited available data, only 40 organizational cities for which statistical data had been available until 1999 are closely examined. The mining cities composed 9 percent of all cities in China at the end of 1999. Their populations accounted for 14 percent of the entire urban population. The mining cities can be divided in terms of type of mines into col- 
liery cities, oil-field cities, metal-mining cities, and nonmetal-mining cities. They mainly locate in the Northeast China and the Central China. The development of mining cities in the former part is however most prominent. On the other hand, although the statistical data indicates that the population size and the scale of mining cities development have been expanding since 1990, the growth rates of economic activities as well as population have been slowing. And the resource crisis, environmental pollution, unemployment, and poverty still accompany with the development of the mining cities.

Based on the part one, the second part presents a case study of Liaoyuan City. The author analyzes the actual problems of industrial stagnation, unemployment, poverty and environmental deterioration, as well as the change of human activity space caused by the problems presented above in detail. The result from Liaoyuan city denotes that, in recent years, the mining cities have become the main problem areas in China after Reformation. In Liaoyuan city, the whole industrial scale has developed unbalanced. The traditional kernel mining industry and its relatives are declining. It is curious that although the unemployment is sharply rising, the expected population movement towards outside city has not occurred. On the other hand the differentiation of residence is increasingly evident. The wealthy social stratum live in the newly developing area, in contrast, the impoverished and unemployment people live in the mining area. Moreover, the habitation was destroyed because of the ground subsidence and other environmental problems in the old mining area. In this thesis, the author analyzes the ground subsidence as an example environmental issue. Its status and damages were investigated through victim visiting. The author found that the environmental issue is localized to a small area gradually.

The third part probes into causation of the change of industrial structure and human activity spaces in mining cities. The author especially pays attention to the affection of Danwei regulation. Danwei that mean workplace in Chinese is basic unit of the production and life activity and plays multiple parts in not only the gross root department of Administration and Party, but also the basic activity space of citizens in China.
The Danwei system is the most developed in mining cities. Therefore the Danwei regulation is important for the economic and social development. In this thesis, on analyzing the structure and specialty of Danwei regulation and its recent trends, the author shows the affection of Danwei regulation to the industrial stagnation, unemployment, environmental pollution and the change of urban human activity spaces. The industrial stagnation in recent years is because the reformation of Danwei regulation that has been implemented since 1990s in Chinese mining cities, but not because the resource depletion and production cost rise. For the same reason, the rationalization of the State and Collective Danwei caused serious unemployment problem. And because of the Danwei regulation, for example the Danwei welfare and the Family registration system, most of unemployed men still strand in the city instead of moving to the other cities. Moreover, the difference in the reformation of Danwei regulations also accelerates the polarization of human activity spaces. In addition, the government does not pay enough attention to the problems of mining area because they consider them as the interior matters of the mining Danwei.

In conclusion, the mining cities have become one of the main problem regions in China. The local area's poverty issues and environmental issues are challenge subjects. Through the case study of Chinese mining cities, this thesis presents the urban sustainability in the process of Chinese economic development.

\section{MATSUSHI Yuki: Triggering Mechanisms and Rainfall Thresholds of Shallow Landslides on Soil-mantled Hillslopes with Permeable and Impermeable Bedrocks. University of Tsukuba, March 2006.}

Rainfall-induced shallow landslides occur in most soil-mantled steep hillslopes as a dominant denudation process in humid temperate regions. This study revealed the hydrological-triggering mechanisms and rainfall thresholds of landslides in adjoining hills with permeable sandstone and impermeable mudstone bedrocks in the Boso Peninsula, Japan. Detailed field and laboratory investigations were conducted to inspect the subsurface structures and to obtain geotechnical 
properties of slope materials. The characteristics of slope hydrology were inferred from pressurehead monitoring and rainfall-runoff observations. An analysis of slope stability identified critical conditions for the several past landslides.

Hydrological triggering of landslides differs with hillslope lithology. Rainwater percolates through the permeable sandstone slope as an unsaturated gravitational flow. The wetting front migration results in a decrease in soil cohesion and causes landsliding at the steep lower part of the hillslopes. In the hillslope with the impermeable mudstone, the hydraulic discontinuity beneath a thin soil layer causes a transient positive pressure head that generates a saturated subsurface storm flow. The reduction in effective normal stress triggers a shallow soil slip at the uppermost part of hollows.

An analysis of the relationship between the magnitude of rainfall and hillslope instability provides a rainfall threshold for landsliding. The rainfall threshold can be expressed by a powerlaw function that combines rainfall intensity and duration. The site-specific combination of rainfall intensity and duration incorporates geotechnical properties of hillslope materials and slope hydrological processes. The hillslope with permeable sandstone has greater critical rainfall and hence a longer recurrence interval than the impermeable mudstone hillslope. This implies the lower potential for landsliding in the sandstone hillslopes, corresponding to the lower landslide activity.

\section{MIYAMOTO Shinji: Vegetational Changes since the Last Glacial from the Pollen Influx in Hokuriku District, Central Japan. Tokyo Metropolitan University, September 2005.}

The results of the pollen analysis by the relative and absolute-value methods of the boring core samples from the Nakaikemi (lowland in $47 \mathrm{~m}$ a.s.l.) and Jakagamiike (mountain district in $700 \mathrm{~m}$ a.s.l.) elucidated that there were a change related to the competition of each main plant for the past $c a .130,000 \mathrm{yrs}$.

1) The relative-value method express larger tendency of changes in pollen production, while the absolute-value method expresses relatively small influx in pollen and detail variation in each taxon. When some types vegetation with the same composition were formed in a short period, the pollen-production change in each taxon could not be detected by the relative-value method. Therefore, the changes of the pollen influx in each taxon could be detected only by the absolute-value method.

2) The productive pattern of the Fagus and Quercus subgen. Lepidobalanus since the Late Glacial in coastal areas of the Sea of Japan elucidated by the pollen analysis using the absolutevalue method showed a reverse tendency of previous studies in other sites. In the coastal areas of the Sea of Japan, Lepidobalanus expanded first and expansion of Fagus followed.

Thus, the absolute-value method can indicate actual changes of the production rate of each taxon, and accordingly one should reexamine previous studies that adapted extensively the relative-value methods.

3) The pollen influx values calculated by the absolute-value are reflected by the increase and decrease rates of the productive frequency of each taxon. It is very difficult to reconstruct the detailed vegetation changes only by the relativevalue method because of the change of vegetation occurs by the competition process of each main taxon. The results of the previous studies made by the relative-value method, however, provide valuable information by revaluating the difference of results between the absolute-and relative-value methods. The reconstruction of the detailed of vegetation needs the pollen analysis by the absolute-value method with the sedimentation rate of each periods and the pollen production rate in each taxon.

4) The evolution of vegetation in the study area shown by the absolute-value method is as follows:

4-1) The Nakaikemi in the coastal lowland of the Sea of Japan.

Cryptomeria expanded rapidly and began to compose a mixed forest with Pinus subgen. Haploxylon in the Last Glacial at the ca. 120,000 yrs BP, Ilex was dominant in the lowland around the moor.

The vegetation with Cryptomeria lasted until ca. 55,000 yrs BP involving a little change of species composition. After that, the vegetation with Cryptomeria was divided into two types: the vegetation type mainly with subarctic conifer 
and that with cool temperate deciduous broadleaved trees such as mainly in Lepidobalanus and Fagus from the ca. 55,000 to 14,000 yrs BP. The value of subarctic coniferous pollen influx was highest during the ca. 20,000 to $17,000 \mathrm{yrs}$ $\mathrm{BP}$ that corresponds to the Last Glacial Maximum (LGM).

The vegetation composed in subarctic coniferous trees shifted to that of Cryptomeria and Pinus subgen. Diploxylon and Betula of cool temperate deciduous broad-leaved trees shifted to Fagus since ca. 14,000 yrs BP. Increase in Diploxylon suggests that the human impact, but that of indicates increase in snowfall on the side of the Sea of Japan. Warm species such as Quercus subgen. Cyclobalanopsis and Castanopsis increase in the Holocene, since $c a$. 10,000 yrs BP.

4-2) Jakagamiike in mountain area of $800 \mathrm{~m}$ in elevation.

Betula as a pioneer tree had started to occupy from ca. 14,000 to 13,000 yrs BP. After that, cool temperate deciduous broad-leaved trees composed of mainly Fagus, Lepidobalanus and Carpinus were formed for the ca. 13,000 to 8,000 yrs BP. Gramineae, nonarboreal pollen, shifted to Artemisia at around 14,000 yrs BP. This vegetation change during the Late Glacial was reflected by the increased in snowfall. Vegetation with Fagus shifted to those with Lepidobalanus and Castanea since ca. 8,000 yrs BP.

5) These vegetation changes show a typical case and mountain environments in the lowland located on the Sea of Japan side area in the Hokuriku district.

\section{MIYAUCHI Hisamitsu: Geographical Study of Changes Observed on Isolated Islands of Okinawa Prefecture after the Reversion to Japanese Administration. Hiroshima University, March 2006.}

The objectives of this study include the investigation of the space structure of the subject area, the isolated islands of Okinawa Prefecture following the reversion to Japanese administration, from the perspectives of time using various economic phenomena.

The frameworks within which approaches for the achievement of study objectives will be made may be described as a system analysis. The world-systems analysis will provide a clue to in- vestigate an economic condition of the subject area for its place and features. The general systems theory may be applied to describing static condition of regional structure of each island, and to dynamics in regional changes by discovering regional structural changes of the isolated islands as a system, which can be caused by response and adjustment to influences exerted by the external circumstances, as well as reorganization processes for the improvement of islands space proactively. In that case, stimulus-reaction systems may come in the following two forms: "the first response form" that is a passive and static response to external impact, and "the second response form" that is an active and selforganizational response to external impact. The system's space level may be divided into two groups: (1) a pattern to compare mutually related areas or regions including settlements on each island and (2) a pattern to investigate relations and links with nationwide areas paying attention to its links to larger cities in the same region of the isolated islands, the subject area.

In this study, various economic phenomena of the isolated islands of Okinawa Prefecture will be examined in regard to the two forms of stimulus-reaction systems using two space level patterns in order to investigate space structure and changes.

The information obtained by this study may be summarized as follows:

Chap. 1 describes the investigation of influences of bridge building on the population and households of islands and comparison among different settlements on an island. The islands level was chosen to be the research subject level in this case and "the first reaction form" was examined. The study of the Island of Hamahiga revealed that about $1 / 4$ of the households accepted additional family members moved in during the first 5 years following the completion of the Hamahiga Bridge. An inquiry survey of the households with moved-in residents was performed in the settlements of Hama and Higa, which showed that there is a difference in the nature and form of the migration. The impact of building a bridge for an isolated island inevitably differs among different settlements since the "initial condition" of the settlement's industry or industrial structure is different which is reflected 
in the impact.

Chap. 2 describes labor shifting of temporary workers who went to Japan proper to work. Naha City metropolitan area served as the largest source of temporary workers absolutely and relatively. Many help-wanted companies sent their staff members to local job selection meetings held by a public job placement office to recruit. There was a tendency that only when sufficient labors had not been secured, Miyako became a target for temporary worker supply source. The study clearly revealed that Okinawa's system to send temporary workers to Japan proper comprises of the main system formed around Naha City metropolitan area and a sub-system formed in Miyako district. This is a case study of the "first reaction form" taking the region (prefecture) as the subject area of this paper.

Chap. 3 explains a case study of Zamami Island which had been transformed into a tourist site by developing diving businesses taking advantage of marine resources of the island. The development of diving businesses for tourism in the 1980's and subsequent years promoted diving shops, hotels and other accommodation services, which enhanced employment. The old timers of Zamami Island also reacted proactively to the changes. Tourist guides in diving were mostly retired fishermen or the children of owners of guesthouses who came back to Zamami. The existing guesthouses take tourist as their guests and tourist guides rent fishermen's boats for visitors to dive, which formed direct or indirect economic links among different sectors on the island. The old timers such as fishermen and guesthouse owners reacted well to tourism development. They also formed a system to transform guesthouse town into a space of siding tourism with guiding service, accommodation service and boat rental businesses. This is a case study of the second reaction form taking the isolated island as the subject area of this paper.

Chap. 4 focuses on the present condition of business formation and tasks of special products manufacturers were analyzed. Paying attention to the function of wholesalers in guiding and supporting manufacturers. Special products manufacturers and wholesalers in solidarity are forming a system to develop and sell special products. The function and relations of a pre- fecture level wholesaler, Okinawa Prefecture Product Public Corporation, and an isolated island level wholesaler, Kumejima Product Public Corporation were studied. The former makes suggestions and work jointly with manufacturers in the development of commercial products making a full use of market information gained through businesses of wholesales and retail sales. The function of the latter in promoting product development is limited to guiding and advising the manufacturers, however this also contributes to the improvement of product quality and helps to deal with other wholesalers smoothly. The relationship between the two public corporations of two space levels is characterized by mutual dependency in the development and circulation of special products of Kumejima. This is a case study of the "second reaction form" taking the regional (prefecture) level as the subject area of this paper.

\section{MIZUMOTO Tadaki: Principal Fault Activity} in the Holocene Time based on Geomorphic Analysis in the Tohoku District, Northeast Japan. Tohoku University, March 2006.

In the present study, seven areas of Tohoku district (Yokote, Kitakami, Shonai, Yamagata, Nagai-Yonezawa, Sendai, and Fukushima) having features of surface faulting and rupturing are examined to determine the timing and amount of displacement of the most recent surface faulting per event, recurrence interval between events, and the vertical slip rate during Holocene. Combined the data from field observations on fault scarplets on the Holocene terraces of different ages with the much data from the previous trench excavation surveys, this paper shows spatio-temporal relationships of fault activity for characterizing of active tectonics in this area.

There are two types for the relation for the pair of uplifting and subsiding region and thrust faults in the area. One is the case where they are bounded by thrust faults on both sides, for an example, Ou backbone range between Kitakami lowland and Yokote inter-mountain basin. Other is the case where thrust faults are developed only on one side, for examples, west-dipping thrust fault zones between Ou backbone range and Fukushima basin-Sendai plain, between Yamagata inter-mountain basin and Dewa hills, and 
between Nagai-Yonezawa inter-mountain basins and Dewa hills.

As a result, all these active thrust faults show the recurrence intervals of 2,000 to 4,000 years, and seismic fault slips per single event of 1.5 to $2.0 \mathrm{~m}$, at most $3.5 \mathrm{~m}$. The average slip rate of each fault during Holocene time is similar in range to that obtained for the deformed late Pleistocene terraces, suggesting that rates of ongoing tectonic deformation in this district have been continuing since the late Pleistocene.

All data on seismic events were plotted on the time-space grids. The resolution of time limit is shorter than 1,000 years. This analysis revealed two types of time-space trends for seismic events. One is concerned with the case where uplift zones are bounded by thrust faults on both sides. The author found in this case that large earthquakes with slip of about $2 \mathrm{~m}$ occurred alternatively on the two fault zones with time interval of 1,500 to 2,000 years. Other is concerned with the case where one-sided faults between mountainous zones and lowland zones are arranged linearly but discontinuously. Once anyone of the fault segments became active, they tend to have been active nearly simultaneously, probably due to seismic triggering.

\section{MOTOKI Masatoshi: Water and Material Balance in the Koise River Basin, Ibaraki Prefecture. RISSHO University, March 2005.}

This study discussed the flow and balance of water and materials based on the idea of LCA (Life Cycle Assessment), which has become an important method in environmental protection policy. The study area is a small river basin of the Koise River, Ibaraki Prefecture, central Japan, where municipal water supply for urban and suburban areas depends on the other river basin and irrigation water is also taken from the outside of the basin.

Water balance including natural, municipal and irrigation water in the basin was quantitatively analyzed using a simple raster type GIS. The amount of artificially supplied and drained water in each grid was estimated by water balance method. The amount of municipal water supply for the basin increased from $1.8 \times 10^{6} \mathrm{~m}^{3} / \mathrm{y}$ in 1965 to $15.6 \times 10^{6} \mathrm{~m}^{3} / \mathrm{y}$ in 1995 . Sewerage system had not been constructed until 1990. Therefore, the great portion of discharge water was untreated. The amount of sewerage discharge water into the sewerage system was $10.3 \times 10^{6} \mathrm{~m}^{3} / \mathrm{y}$ in 1995. Since the sewerage treatment was developed every year thereafter, the untreated discharge water reduced accordingly, and the amount became $5.4 \times 10^{6} \mathrm{~m}^{3} / \mathrm{y}$ in 1995 . The ratio of clear water to polluted water was estimated from the amounts of natural, municipal and irrigation water and that of polluted water. The amount of irrigation water supply tends to be influenced by precipitation. The amount of water consumed and drained in the paddies is proportional to irrigation water supply. Comparison of the artificial water supply to the natural runoff amount suggests that irrigation water does not exceed the effective precipitation in most of the river basin. The ratio of untreated discharge water to natural runoff was examined for each grid. As a whole, the influence of artificial discharge is still small but discharge water influences water balance in some parts of the river basin. Artificial water supply, including the municipal and irrigation water, has been increasing every year in each grid in the basin.

The amount of the household waste was also estimated from the record of refuse truck. The distribution of the household waste was also shown in GIS map data. Although household waste data were not well arranged as those of artificial water, calculation of household waste per capita unit enabled the mapping of household waste distribution in 1980 and 1995. Because area difference in the amount of household waste in the basin has been disappearing with the change of lifestyle and the flow is considered to be approximate to artificial water transfer. The amount of household waste increased 2.2 times from 1980 to 1995 in the basin.

Because the data of household waste flow are not enough even at present, per capita unit was applied to the preparation of the distribution map and to the evaluation of the flux of waste materials. Then the material balance was completed.

It must be emphasized that waste water occupies more than $96 \%$ (by weight) of the total waste from the Koise River basin. The budget of water must be taken into consideration of an environmentally sound community. 
MURANAKA Akio: Spatial Economic Evaluation for the Benefit of Environmental Resource Management by Stated Preference Measures. Ritsumeikan University, March 2006.

In this dissertation, we discuss the spatial issues associated with the benefits of farm and forest land management. Further, we make new analytical modifications to the contingent valuation method (CVM). The benefit is defined by consumers' maximum willingness to pay (WTP) for land conservation. This thesis is characterized by its focus on (1) the spatial spill over effect of the benefits, (2) the spatial distribution of the goods subjected to study and (3) the willingness to work (WTW) towards land conservation. After evaluation, the following results were obtained:

(1) We evaluated the benefits of rice terrace conservation. The results revealed that the residents living near the rice terrace obtain higher benefits than those living further away from the field. This clearly indicates that the benefits of rice terrace conservation spill over as the distance decay effect. It also constitutes important information when governments impose financial burdens for conservation on the residents; in this case, the governments need to ensure the regional equity of this burden.

(2) We evaluated forest management in order to reduce the risks of Japanese cedar pollinosis. We also proposed new models with multizonal contingent markets based on CVM for valuing the environmental goods that are widely distributed in the study area. These models allow us to estimate the management benefits per unit area. In addition, we discussed the priority region and investment destination of forest maintenance.

(3) We estimated the benefits of forest management using forest volunteers. It should be noted that physical and financial support remains a serious policy issue. Therefore, we investigated WTP and WTW with regard to forest conservation. The result revealed that the values that an individual assigns to forest conservation are particularly influenced by that individual's sense of belonging to a society and previous experiences in visiting the forest.
NAGATA Rena: Response of Summer Atmospheric Circulation over East Asia to SST Variability in the Tropical Pacific. Tokyo Metropolitan University, September 2005.

The East Asian summer monsoon has notable special complexity. It covers Japan, China, Taiwan and Korea. The SST over the tropical $\mathrm{Pa}$ cific has been generally recognized as the most prominent factor affecting the East Asian circulations. The features of the general circulation over East Asia associated with the variability of the tropical Pacific SST are studied using the European Centre for Medium-Range Weather Forecasts (ECMWF) ERA-40, OLR (outgoing longwave radiation) and SST data.

To understand the annual and intraseasonal variation of the NPSH, we defined the western edge of the NPSH (subtropical high index; SHI) using pentad mean 500-hPa geopotential height data (from pentad 31 to pentad 49). Although the SHI retreats eastward in the mid-1980s, southwestward expansion of the SHI is observed since 1980. The seasonal evolution of the SHI exhibits a large interannual variability. During the year when the NPSH displaced westward (WD year) and southward (SD year), the SHI exists in the west of $130^{\circ} \mathrm{E}$ for all pentads. However, the eastward retreats after pentad 41 is not obvious in WD year. The correlation coefficient was calculated to explain the relationship between SHI and the tropical Pacific SST. The zonal component of SHI (SHI zonal) has the strong connection of only the eastern tropical SST, while the meridional component of SHI (SHI meridional) strongly related to both the eastern and central tropical Pacific SST. On the other hand, there is no significant relationship between SHI and the western tropical SST.

We also examined the circulation cell changes over the North Pacific related to the NPSH variations. The North Pacific shows the anomaly of the reversal Hadley circulation over the western Pacific, a single meridional cell over the eastern Pacific in WD year (SD year) compared with ED year (ND year). This anomalous circulation cells cause the southwestward extension of the NPSH. After pentad 41, associated with the eastward movement of the high SST over the tropics, the strong rising motion anomalies are observed particularly in the area $120^{\circ}-100^{\circ} \mathrm{W}$ in WD year rel- 
ative to ED year. On the other hand, after pen$\operatorname{tad} 41$, the ascending anomaly area moves westward and is located near the central tropical $\mathrm{Pa}$ cific and the descending area shifts from $120^{\circ}-$ $130^{\circ} \mathrm{E}$ to $100^{\circ}-110^{\circ} \mathrm{E}$ in $\mathrm{SD}$ year relative to $\mathrm{ND}$ year. Thus, the westward shift of the circulation cell anomaly is observed in SD year after pentad 41. The presence of the westward shift of the NPSH is due to the regional variations of the tropical Pacific SST.

The present study focused on the general circulation variability over East Asia and suggested that the general circulation over this region has remarkably changed after the 1980s. The SST over the central and eastern tropical Pacific has a great influence on the circulation cell variations over the North Pacific. The seasonal variability of the general circulation is due to the regional difference of SST warming. As Nitta and Yamada (1989) suggested that the SST warming is obvious over the central and the eastern tropical Pacific, the main factor of the recent circulation changes over the North Pacific and the NPSH variability is the central and eastern tropical SST warming. The impact of the western tropical Pacific SST may be less significant than that in these regions. This is probably due to the compensating downward motion for the convection over the tropical Indian Ocean.

\section{NAKAJO Akihito: Research on Maintaining the Life of Elderly People in Hilly and Mountainous Areas, and on Related Mechanisms. Hiroshima University, February 2006.}

In this thesis, the author has attempted a geographical investigation of elderly people living in hilly and mountainous areas in Japan, with a particular focus on the ability of these elderly people to maintain their life in these regions, and on the related mechanisms. In order to approach this issue, the author has introduced a "concept of strategy" in this research, and has positioned the overall approach by which elderly people achieve their lives as a "life strategy." The author then examined the behaviors of elderly people working independently to maintain their life even while they are subject to the various restrictions placed upon them by the environment.

There are two main conditions required for elderly people to maintain their own life; namely: (1) bearing unique responsibilities in the community, and (2) receiving support that is embedded in the regional society.

The first point, the role of the senior in the community, was demonstrated through analysis in first chapter and second chapter. That is, the author positioned elderly people as the "bearers" of the community, and focused on the behavior of elderly people who are aiming to maintain the regional society and secure economic activities through participation in community activities and production activities. The goal of elderly people' activities in the community is to increase the stability and quality of life, and the results of these activities could be considered the "resources" for life strategies.

In former Takamiya-cho in Hiroshima Prefecture, which is examined in first chapter, elderly people bear the responsibility for farming and other lifestyle activities, thereby assuming a central position in the creation of the community. It became clear that regional municipal organizations which lead community-building create venues for activities by taking advantage of the skills and knowledge that elderly people possess, and that in this context the elderly people fulfill their role of maintaining the regional society. Venues for production activities promote the recovery of social solidarity and the creation of reasons for living.

In the Gohoku region of Kochi Prefecture, which is examined in second chapter, community activities are sluggish, so elderly females undertake agri-processing independently, without receiving any support from the regional society. In order to avoid the friction with elderly males that would arise from conducting these activities, these women organize their own groups under the umbrella of village organizations, or make adjustments in terms of the time and location of lifestyle activities. As a result of the efforts of these women, the venues for production activities created by these elderly women have become a new venue for community activities that also draw in senior males.

In third chapter and fourth chapter, the author conducted an analysis of the support received by elderly people. For elderly people faced with the issue of aging, support received 
from others is an important resource in the development of life strategies. In many cases, however, the elderly people living in hilly and mountainous areas life apart from their children, and it becomes necessary to obtain support from parties other than children who have chosen to live elsewhere. In many cases, the form in which this support is received influences the maintenance of life.

In third chapter, based on a questionnaire survey conducted in Miyoshi City, Hiroshima Prefecture, the author clarified the latent needs of elderly people in reference to the "others" who are the main providers of support (the support source). These elderly people had a high degree of needs in reference to the neighbors who lived in closest proximity to themselves, but depending on the village in which the elderly people lived, neighbors were not necessarily a stable support source. Under these circumstances, the author found that the welfare activity organizations in which regional residents participate were positioned as a new support source, and played a significant role by compensating for the "hollowed-out" support from neighbors.

In fourth chapter, the author examined the construction of support networks by elderly people in Iwami-cho, Shimane Prefecture. In this region, the author found that support is not provided unilaterally from others, but that in some cases, the elderly people take a proactive stance by actively constructing social networks. The construction of networks, however, is significantly affected by location; elderly people tend to establish closer interactions and introduce support relationships with others who live near to themselves, and this has made it possible to achieve life on a spatial scale with a broad scope. As people grow older, however, their ability to incorporate support from others deteriorates, and others provide support regardless of the intent of the elderly people. Flexible changes in support networks, in keeping with the aging process, support the life of elderly people.

In this thesis, through a series of observations, the author has determined that elderly people living in hilly and mountainous areas develop their own life strategies using as resources their own knowledge, skills, and social relationships, thereby taking a central role in the maintenance of their own life.

\section{NISHI Ritsuko: Residence Space of Single Elderly People in the Urban Periphery in Tokyo Metropolis: Approach of Life History Method. Ochanomizu University, March 2006.}

This study aims to represent residences space of single elderly people in the urban periphery in Tokyo Metropolis. The present research focuses on how single elderly people as the subject can be able to form residences space, and pays attention to three parts of residence space. One is a house including equipment and facilities. The second is a public house for the elderly (the Silver Peer Housing Project) and vicinity region. The third is a place where the elderly individuals form social relations in the residence area, it pays attention to the Kotobuki halls which are one of facilities for elderly people. In this study, a concept of residences space contains a consecutive area from the house to the vicinity region. That is a concept including to access to city amenities, personal residence records, and changes in meanings of the place according to ageing.

The object region is Bunkyo Ward in Tokyo. That locates in the urban periphery in Tokyo Metropolis. It has built up over time various urban amenities and social infrastructure, and it has the characteristic of the urban periphery.

The Silver Peer Housing Project is a system that Tokyo Metropolitan Government began in 1988. This project targets low-income single elderly people who cannot afford privately owned housing. Bunkyo Ward makes the ordinance concerning this business, and based on this ordinance, Bunkyo Ward is managing the house equipment and the resident. In the Silver Peer Housing, there is facilities' equipment of barrierfree. In addition, "life support members," persons who extend aid in case of emergency are residing there.

Kotobuki halls are facilities where Bunkyo Ward had been set up so that the elderly people might spend old age comfortably in the region. From 1971 to present, 17 facilities were set up in the district. All of them have the bathroom, and the use of the bathroom is free. Moreover, those have some rooms, "senior clubs" groups based on resident's associations are acting there. 
This research uses the life-history method. The life-history method is a technique for addressing the focus to the individual. By the lifehistory method, it became possible to connect the attribute, experience, sense of values of single elderly people and the place. To express the rich reality of an individual's life-history, narratives obtained through interviews are complemented by the use rich of supporting materials. In the field of geography, maps are used to add detailed regional description to narratives. As a consequence, privacy protection concerns arise when publishing the result of research.

The following points are discussed in my thesis:

1) Single elderly people are excluded by the residential real estate market first of all, because they are regarded as a risk. Many of low-income single elderly people resides in a private rented house. When the rented house is remodeled, they cannot bear the fee. As a result, they will rely on a public housing policy. While the residents express their gratitude, they feel the difficulty of the interpersonal relationships of the residents. For that reason, the residents keep ahead relations to previous residences. 2) Almost public houses for elderly people are collective houses (the Silver Peer Housing), there is a problem of the gathering of single elderly people. One problem is in the relation to the local community. The Silver Peer is labeled as 'group of low-income elderly people who does not have the relatives'. In addition, the building named the Silver Peer makes the residents' attribute plain. The residents do not have neighbors to rely on for support. Disabled residents increasingly need continual support in their daily lives. However, the Nursing Insurance System puts very strict limitations on the types of service they are eligible for. They use traffic infrastructures and city amenities according to individual body functions. 3) Single elderly people need to build social relations in the area where they live, not only for emotional support, but also for practical reasons: support resource and safety net for crisis management. Kotobuki halls open in Bunkyo Ward as district facilities for elderly people living in the area. Kotobuki halls play a stimulating role in the gradual creation of relationships between elderly people, shared values that are characteristic of the "society of the old". Kotobuki halls play an important part in the creation of an environment where elderly people can continue to live. However, the administration decides the abolition of facilities for finance reform.

\section{OBARA Norihiro: Rural Restructuring and Its Sustainability in Bad Hindelang, Bavaria, Germany. Tokyo Metropolitan University, March 2006.}

This study analyses rural restructuring and its sustainability in rural Bavaria, Germany, using an example of Unterjoch, which is located in a mountain area. In Unterjoch, the sustainable rural system is characterized by more extensive and differentiated land use since the 1990s. In general, the intensive use of rural land has led to pluriactivity in rural Europe. A recent trend is the attraction of rural tourism.

Until the 1980s managements achieved pluriactivity by combining intensive farming in grassland with forestry supported by price support, guest house management and works in service sector in urban areas. But intensive farming degraded grassland and forest that played an important role not only for production but also for attracting rural tourism. At the same time, the number of overnight guests decreased, and the number of day-trip tourists increased in Unterjoch. In addition, since the 1990s, EU has worked out a policy to reduce price supports for farming managements and restrict the overuse of grassland and forest by reforming Common Agricultural Policy.

In response to these socio-economic changes, managements in Unterjoch diversified pluriactivity by adding organic farming and direct marketing for the purpose of sustaining grassland and forest as the space for production and attraction for rural tourists. Farming managements started to use grassland and forest extensively for organic farming. Furthermore, they re-used Alp in the mountain area abandoned during the productivist era, according to the criteria of the organic certification group. In addition, managements restructured the system in which they produced and sold dairy farming products that utilized local resources. Moreover, managements are now able to receive subsidies from agri-environmental policy in spite of the reduction of 
price supports owing to the reform of Common Agricultural Policy.

From the view point of community-based development, the vertical differentiation of spatial use makes it possible for farming-oriented managements and tourism-oriented management to co-exist with a common purpose of sustaining rural space for tourism. The space for farmingoriented management is made up of grassland, forest and Alp in mountain area, whereas the space for tourism-oriented managements consists of grassland, forest and housing area. As a result, a community-based development model named 'Öko-modell Hindelang' is promoted, which is designed to promote the extensive use of grassland and forest for sustaining the attraction for rural tourists and direct marketing of agricultural products to rural tourists.

\section{OISHI Masayuki: Study of New Method for Correlation of Volcanic Products between Distal and Proximal Areas based on the Chemistry of Phenocryst: Example of the Products from the Yatsugatake Volcano, Central Japan. Tokyo Metropolitan University, March 2006.}

This study aims to establish a new method for identification and correlation of volcanic products. Correlation of tephras, a kind of volcanic products, generally relies on the properties of volcanic glass shards. However, the method using volcanic glass shards is not applicable for volcanic products strongly altered by weathering or welding. This study proposes a new method for identification and correlation of volcanic products using two-pyroxene, hornblende, and plagioclase phenocrysts. The refractive indices of orthopyroxene and hornblende, and composition of the major element in orthopyroxene and plagioclase phenocrysts were measured to test whether these can be criteria to distinguish and correlate the products. The products measured were originated from the following volcanic events: (1) 3.1 ka eruption of Kawagodaira Volcano (Higashi-Izu Monogenetic Volcano Field); (2) A.D. 1783 eruption of Asama Volcano; (3) Middle of 6th century eruption of Haruna Volcano; (4) $14 \mathrm{ka}$ eruption of Nantai Volcano (Nikko Volcano Group); and (5) A.D. 1914 eruption of Sakurajima Volcano.
It was confirmed that the phenocrysts in distal fallout tephras have similar refractive indices and major element compositions to those of proximal deposits such as welded pyroclastic rocks and/or lavas produced by the same eruptive event, showing no relationships with the distance from the source. This suggests that those properties provide criteria for correlation between different types of volcanic products originated from a single eruptive event. The $\mathrm{Mg}$ value $(\mathrm{Mg} \# ; \mathrm{Mg} /(\mathrm{Mg}+\mathrm{Fe}) \times 100)$ of orthopyroxene phenocrysts contained in the products derived from the same eruptive event have a very narrow range, and differ significantly from those in the products of other eruptive events and other volcanoes. On the other hand, the refractive index of hornblende phenocrysts and the anorthite content $(\mathrm{An} ; \mathrm{Ca} /(\mathrm{Ca}+\mathrm{Na}) \times 100)$ of plagioclase phenocrysts are quite variable. And then, the complicated chemistry of hornblende and plagioclase phenocrysts will provide a useful tool for identification and correlation of volcanic products. In using this method, it is needed to measure numerous phenocrysts, and to use line analysis on plagioclase phenocrysts, which are commonly forming the zoning structure.

The results show that the chemistry of phenocrysts often changed unit by unit in an eruptive event. The products produced by the eruption of Haruna Volcano in the middle of 6th century are a typical case. This means that it is needed to analyze all units of a volcanic product. By comparing chemistry of phenocrysts between proximal and distal areas, a certain distal unit correlative to one in proximal area is possibly detected. By this correlation, we can reconstruct the detailed sequence of an eruptive event.

Using the method presented above, we determined the source of the Yatsugatake Younger Tephra Beds in the latter half. The source of these Plinian pumice-fall deposits (with the exception of the Yt-Pm4) was approximately estimated to be in the Middle Yatsugatake area, on the basis of spatial variation of thickness and grain size. The chemistry of orthopyroxene and clinopyroxene phenocrysts contained in lavas and welded tuffs reveal that the source of Yt-Kw in the vicinity of Ioudake, and that of Yt-Pm1, Yt$\mathrm{Pm} 2$, and Yt-Pm3 in the Tengudake area. Yt-Kw was created by an eruption at $c a .171 \mathrm{ka}$ with the 
formation of the Ioudake Welded Tuff. Yt-Pm1, Yt-Pm2, and Yt-Pm3 were produced at the same time of effusions of the Tengudake Lower, Middle, and Upper lavas, respectively.

The eruptive history of the Middle Yatsugatake area in the last 200,000 years is summarized as follows. Two lava flows, two Plinian pumice-fall deposits, and one pyroclastic flow were produced by the eruptions in the Ioudake area, whereas seven lavas, three Plinian pumice-fall deposits, and three pyroclastic flows associating two welded tuffs were produced in the Tengudake area. The area between Kita-Yokodake and Tengudake area, lavas were effused on the monogenetic craters and lava domes were often formed. Chemistry of phenocryst does not vary within each area, but does differ from one area to others. In all areas, mafic and felsic magmas were mixed just before each eruption.

\section{OKAMOTO Toru: Environmental Change Inferred from Properties of Superficial Deposits and Speleothems in the Kitakami Mountains, Northeastern Japan: Human Impact in the Akka Karst. Tokyo Metropolitan University, September 2005.}

This study uses a multi-proxy approach involving tephra, past land use, soil distribution and property, speleothem isotopes, and archeological information to reconstruct palaeo-environmental changes of the Kitakami Mountains, northeastern Japan, in the late Quaternary. Although many studies have discussed human impact on present landscape of the mountains, most of them lacked continuous and long-term dating control. The focus is thus on the human induced changes during the Holocene in the Akka Karst located in the northeastern part of the mountains.

The marker tephras in and around the Akka Karst have been identified as follows: Towada- $a$ tephra (To-a: AD915), Towada Chuseri tephra (To-Cu: $6 \mathrm{ka}$ ), Towada Nanbu tephra (To-Nb: $8.6 \mathrm{ka})$, Akita-Komagatake Yanagisawa tephra (Ak-Y: 11.6-11.9 ka), Akita-Komagatake Koiwai tephra (Ak-K: 12-13.5 ka BP), Towada Hachinohe tephra (To-H: $15 \mathrm{ka}$ ), Iwate Oide tephra (Iw-Od: 35-50 ka), and Toya tephra (Toya: 112$115 \mathrm{ka}$ ). These tephras can be also used as an indicator of slope stability in the Last Glacial. En- vironmental change of the Last Glacial is regarded as a general background when assessing the anthropogenic impact on natural change, because drastic human impact may expand since the early Holocene. Based on tephrachronological investigations, periglacial processes were dominant on the slopes of the karstic plateau in the cold phases of the Last Glacial. The periods of slope formation caused by periglacial processes in the Akka Karst were inferred to be around $50 \mathrm{ka} \mathrm{BP}$ and 30 to $10 \mathrm{ka} \mathrm{BP}$, which are in accord with those of mass movement in the Central Kitakami Mountains, and of involution and soliffuction lobes in the Northern Kitakami Lowland. Moreover, wind-blown biotite in soils on karst, which originated from granitic rocks, implies that bare ground affected by periglacial processes was distributed over the summits of adjacent granitic mountains during the late Pleistocene. Accordingly, allogenic deposits on karst have helped to reconstruct environmental conditions in non-limestone areas as well as in limestone areas.

In the central Kitakami Mountains, the properties and distributions of present-day soils reflect three types of land use in the early 20th century: grasslands, secondary forests and oldgrowth forests. Soils of former grasslands were classified as melanic Andisols, which were characterized by their intensely dark color, high carbon content and the presence of A-type humic acid. Soils under former old-growth forests displayed high $\mathrm{C} / \mathrm{N}$ ratios and the presence of $\mathrm{P}$ type humic acid in their A horizons, and were thus classified as Podzolic soils. The soils of former secondary forests were classified as fulvic Andisols (Fulvudands), and contained B-type humic acid and macroscopic charcoal fragments. Therefore, melanic Andisols can be used as an indicator of past grassland vegetation. In contrast, Podzolic soils under old-growth forest were less disturbed than other past land uses. The thickness of dark-colored A horizons in the former grasslands appears to depend on how long, they were maintained as grassland vegetation: the longer this period, the thicker the dark-colored humus horizons. The starting period of formation of melanic Andisols, which was caused by vegetation change from forest to grassland as a result from human activity, could be traced back 
to several thousand years ago on the basis of ${ }^{14} \mathrm{C}$ dating and tephras age. The replacement of deciduous forests by grasslands occurred later, since the last 300 years, in high elevations far from human habitations. Evidence provided by ${ }^{14} \mathrm{C}$ dating and recent archeological studies suggests that secondary forests have since medieval times been used mainly as charcoal and firewood. These results help to interpret vegetation transition between forests and grassland throughout the Holocene.

Melanic Andisols are also recognized in the Akka Karst. Based on age of tephras in soils, the starting periods of formation of melanic Andisols in the Akka Karst were divided into two: about $9 \mathrm{ka} \mathrm{BP}$ and after about $5 \mathrm{ka} \mathrm{BP}$. The $\delta^{13} \mathrm{C}$ values of soils appear to be very useful for the interpretation of transition between forest (C3 plants) and grassland (C4 plants) as well as carbon content, $\mathrm{C} / \mathrm{N}$ ratio and types of humic acid in soils. $-19.8 \%$ of $\delta^{13} \mathrm{C}$ value for melanic Andisols implied that $51 \%$ of organic matter derived from C4 plants, such as Miscanthus sinensis. In contrast, $\delta^{13} \mathrm{C}$ values of non-melanic Andisols ranged from $-22.69 \%$ to $-21.94 \%$, suggesting that $70 \%$ of organic matter derived from woody vegetation (C3 plant). In the Akka Karst many archeological sites during the Jomon Period (12$2.4 \mathrm{ka}$ BP) distribute on the fluvial terraces and the caves along the rivers in the Akka Karst, of which distribution well coincide with that of melanic Andisols formed since about $9 \mathrm{ka}$ BP. Human activities gradually expanded on the karstic plateau, leading to expansion of grassland vegetation, in turn resulting in formation of melanic Andisols after $5 \mathrm{ka}$ BP. These suggest that human-induced deforestation and maintenance of grasslands caused the formation of melanic Andisols in the early-middle Holocene. During the 17-19th centuries an iron smelting industry thrived in the northeastern part of Kitakami Mountains, the forest surrounding the ironworks were used as fuel and charcoal wood and repeatedly cleared. Following the decline of the iron smelting industry, vegetation became secondary forests dominated by Quercus mongolica var. grosseserrata.

Three stalagmites collected from Uchimaki-do Cave were analyzed to examine whether their stable carbon and oxygen isotopic records are used as proxy of palaeo-environmental change for this region. The U2 and U3 stalagmites were deposited in isotopic equilibrium because of no correlations between $\delta^{13} \mathrm{C}$ and $\delta^{18} \mathrm{O}$ values. On the other hand, U1 stalagmite has a strong and abrupt enrichment in the near-top measurements. Thus, it is likely to be affected by kinetic isotope effect of air circulation from the cave entrance which was induced by the enlargements of cave entrance in the $1970 \mathrm{~s}$. The shifts of $\delta^{13} \mathrm{C}$ and $\delta^{18} \mathrm{O}$ values of stalagmites in Uchimaki-do Cave replicate well, suggesting that both records reflect regional environment changes. The $\delta^{18} \mathrm{O}$ values in the upper part of U1 and U2 stalagmites tend to increase, which may respond to increase in air temperature after the end of the Little Ice Age. Therefore, the speleothem $\delta^{18} \mathrm{O}$ values would reflect the changes in air temperature above the cave. High $\delta^{13} \mathrm{C}$ values of Uchimaki-do stalagmites have been mainly affected by C4 grasses on surface, because melanic Andisols derived from grassland vegetation occurred above the cave. Since present vegetation above the cave comprises deciduous forests, a rapid decrease in $\delta^{13} \mathrm{C}$ in the near-top measurements of U2 probably reflects the replacement of $\mathrm{C} 4$ grass by $\mathrm{C} 3$ woody vegetation in the last several decades. In addition, the $\delta^{18} \mathrm{O}$ records in the middle-upper part of U1 and U2 stalagmites are similar to those for the last 500 years of stalagmite S312 collected from Shihua Cave near Beijing, northeastern China. Lower and higher values of $\delta^{18} \mathrm{O}$ in the upper to middle part of Uchimaki-do stalagmites might reflect the historically documented variability, Little Ice Age and Medieval Warm Period, respectively. Consequently, Uchimaki-do stalagmites have a high-potential for indicators of the Holocene climate change not only in the Kitakami Mountains but also in northeastern Asia.

Increasingly there is a need for improved palaeo-environmental records at both high spatial and high temporal resolution to understand past climatic change in the terrestrial regions and aid future climate predictions. As the above mentioned, both surface and subsurface sediments of the Akka Karst contain high-resolution palaeo-environmental records that preserve long sequences of the late Quaternary. Speleothems are particularly multi-proxy palaeo-environment 
archives with precise time control using U-series dating and counting annual banding. Therefore, further accurate and continuous dating of speleothems of the Akka Karst will illustrate more precise reconstruction of environment changes in the Kitakami Mountains, permits comparisons with other proxy records elsewhere and distinguishing of their place to the global climate change.

\section{OMATA Toshio: Regional Industrial Development in Soviet and Post-Soviet Russia: Locational Changes in Industry Associated with Social System Conversion and the Transitional Period. Rissho University, March, 2006.}

Since the collapse of the USSR in 1991, Russia has undergone a period of radical transformation, moving from a socialist system to a new stable society. Although the ultimate purpose of this study is to clarify the relationship between this transition and its ramifications on social transformation and associated changes in the regional structure of the economy, two areas of focus are proposed at present. These are a reexamination of the regional structure and location of industrial activity in the soviet era, and to investigate extant industrial development at both regional and settlement levels.

We found that Soviet Russia became an industrial power through a flourishing munitions industry, which then subsequently provided other republics within the union with natural resources and many products according to the division of labor within the USSR. On one hand, the vast territory of Soviet Russia, earlier equal development policies, a resource-dependent economic structure and other factors are thought to have contributed toward the regional dispersion of industrial activity. However, within the context of the distribution, type and function of industrial activity, the realized dispersion was rather limited due to the needs of rapid industrial development, the centralized sectoral economic system, the harshness of the climate and other factors, which inhibited the distribution of industrial activity. Therefore, the culmination of these factors resulted in the development of industrial centers both within the core region, from the viewpoint of the core-peripheral relationship, and in the large cities such as Moscow; one of the most expansive industrial agglomerations at the settlement level.

Within the context of the second theme, the process of trade liberalization in the 1990's resulted in a marked reduction in industrial production with different industries being affected differently. While the regional structure of industrial activity inherited from the soviet era has essentially remained unchanged, there has been a tendency toward change in the latter half of the 1990's. The most remarkable changes have led to a shift in industry toward the larger cities, such as those in and around Moscow and Saint Petersburg at the settlement level. There has also been a westward movement at the level of the whole country, as well as a greater focus on the core and the intermediate regions relative to the peripheral regions compared to the soviet era. In the changes after 1995, foreign investment has had a marked influence on industrial location, and industrial activity has gradually moved toward the coastal areas.

The locational changes in industry have generally occurred more slowly than expected. This is not only because the transitional process is an inherently slow process, but also due to the combined action of the three factors that directly affect industrial location, namely, access to natural resources, geographical inertia and the longtime existence of both favorable and unfavorable locations.

\section{OTSUKA Toshiyuki: A Study on the Regeneration of the Central Urban Area in Medium-scale Cities in Japan. Nagoya University, March 2006.}

The purpose of this study is to clarify the transformation mechanism of a central urban area in medium-scale cities from a viewpoint of changes of urban function accumulation after bubble economy collapse, and also it is to show the regeneration directions of a central urban area in the low economic growth period. The results are summarized as follows.

The changes of urban function accumulation in a central urban area are related to macro-environmental changes such as economic situation or industrial structure closely. On the other hand, they are controlled by individual factors 
such as city population scale, the city location, the administrative participation, corporate strategy, a building condition, peripheral environment greatly. In metropolitan areas, urban functions accumulate based on a market force. However, in medium-scale cities having only a small market, the administrative participation on the basis of citizen consciousness influences urban function accumulation.

Surroundings such as progress of service economy and diversification of a lifestyle changes greatly. A central urban area should follow the regeneration courses corresponding to those changes. It is unrealistic to forcibly introduce commercial functions into the downtown area that will not be located in on a market force. It is necessary to receive frankly that a central urban area changes into a residential area, and to find the new ideal of a central urban area.

In metropolitan areas, households intending the downtown area residence are increasing recently. There are in some degree potential demands for the downtown area residence in medium-scale cities depending on a car greatly, and therefore the downtown area residence will appear if even condominiums are supplied. But therefore it is necessary for houses having the same standard in dwelling size or parking lots as a detached house in the suburbs to be supplied. Furthermore, the convenient living environment such as a hospital or a store is indispensable.

Because of the location of urban functions at the suburbs, urban function accumulation in a central urban area deteriorates. However, a lot of urban functions such as a store or a hospital are still located there. Accordingly, for the elderly who cannot use a car freely, a central urban area is comfortable to live.

While various urban functions such as living, working, gathering, resting are related mutually, the city repeats the growth and the decline. Therefore, for regeneration of a central town area in medium-scale cities, it is necessary to take various measures such as a residential policy or an employment policy in addition to commercial revitalization policy.

As industrial structure changes, central urban areas change from a production place into a sale place, and change into a offer place of information and service or a life place. A central urban area is not same as a central commercial district. The meaning of center changes from commercial center into living center.

The commercial place offers abundant products and service to us and the employment place brings us income. In the times when the material richness was demanded from, these economic centers were the city center. However, in the times when the mental richness is pursued in, the history and culture on the basis of our life are very important. And in such times urban areas will continue functioning as a central place even if economic functions deteriorate. Recently the changes of urban function accumulation to be seen in a central urban area of small-scale or medium-scale cities are not based on the economic efficiency. These phenomena are explained by the social significance that has been formed with a change of a value system.

Spatial transformations of a central urban area are brought by two forces called "centripetal forces" and "centrifugal forces". Backed by motorization and progress of information and communication technology, urban structure changes greatly in a dispersion direction. However, the force from the outside to the inside will act on changes of urban structure powerfully more than before, considering the times backgrounds such as low economic growth, population decrease, aged society, high interest to an environmental problem. In other words the structure of a central urban area in medium-scale cities is reduced relatively while receiving both centripetal forces and centrifugal forces.

In a reorganization process of central urban area structure, I think that the land use will advance in a composite direction instead of a homogeneous direction. Because it is difficult that all of the large-scale commercial space that hollowed out is supplemented by the same function. Combinations of plural functions are necessary. In other words the central urban area structure will transform in a mosaic-shaped in both plane and vertical plane.

In the low economic growth period, I think that a central urban area will regenerate with composite residential functions and commercial functions in medium-scale cities. Above all, big changes are expected in the fringe district of a central urban area, because that place is the old 
city core, and it is a symbolic place, and it is provided a lot of administrative supports. In addition, the local merchants and landowners had a sense of crisis early and took various measures because the decline was remarkable. In other words because of its marginal qualities of both commercial and residential functions, the fringe district of a central urban area has much potential for regeneration with composite functions.

\section{A.B.M. Kamal PASHA: Holocene Geomorphic History of Alluvial Lowlands and Their Environmental Changes under Differing Relative Sea Level Regimes along the Fukushima Coast, Northeast Japan. Tohoku University, March 2006.}

The present study discussed about three selected areas in Fukushima coastal region as Soma, Haramachi and Namie coastal plain with emphasize to alluvial sequences and sedimentary environments to demonstrate the link between the evolution of the coastal barrier and evolving nature of marsh deposits of the back barrier region as well as the geomorphic development of coastal lowlands. Moreover, this study carried out the paleo-environments and geomorphic changes of the selected study areas in Fukushima coast. It also presented a model diagram of the Holocene sedimentary structure and sequences of the shallow valley fills in a microtidal wave and fluvial dominated settings, based on detailed facies and chronostratigraphic analyses, grain size analyses and $\mathrm{FeS}_{2}-\mathrm{S}$ analyses. The model has been drawn as examples from general sedimentation of the Soma coastal plain. The specific purposes are as follows: (1) To understand and reconstruction the geomorphic history with environmental changes of the study areas. (2) To examine and evaluate the relative importance of possible sedimentary processes and environments of geomorphic development of the alluvial lowlands. (3) To demonstrate the link between the evolution of the coastal barrier and evolving nature of the back barrier region. (4) To draw a model diagram of the Holocene sedimentary structure of the shallow valley fills in a marine wave and fluvial dominated setting: examples from the Soma coastal plain; and (5) To carryout the paleo-environment and geomorphic changes of the selected study areas.
The shallow valleys of the study areas in fills have been strongly influenced under differing relative sea level regimes, in particular on their facies, systems and stacking patterns. The Latest Pleistocene-Holocene deposits beneath the lowlands of selected coastal plains as sedimentary sequences are divided in to the following five depositional patterns: (1) The Lower Gravel layer as Basal Gravel (BG) unit is fluvial in origin, which were deposited during low stand sea level in the Last Glacial stage. The huge accumulation of gravel as the Basal Gravel deposits might have been brought on by the overloaded streams which carried much detritus as the production of the strong physical weathering under glacial or peri-glacial conditions. This Basal Gravel deposits indicate probably somewhat long transportation by the river and this fact suggests more powerful fluvial action of the days than that of present. This BG deposits corresponds to braided river systems. (2) The Lower Terrestrial Sandy (LTS) unit, which were deposited in fluvial environments during the early transgression stage. (3) Marine Clay (MC) unit, which were deposited in inner bay environments during early Holocene transgression stage. (4) The upper marine Sandy (UMS) unit, which were deposited in shallow marine and lagoon environments as well as some times cove conditions and (5) The Upper Terrestrial Sandy (UTS) unit, which were deposited in the Holocene regression stage. The upper most position of this unit considered as the back marsh deposits.

The sedimentary sequences are considered to have been deposited in the following background. First appearances of past sea area in the Soma plain is evidenced in the lowest and closest part of the MC unit to the shore about $25 \mathrm{~m}$ below the present sea level while $20 \mathrm{~m}$ below the present sea level in Haramachi plain and in Namie coastal plain it was $27 \mathrm{~m}$ below the present one. According to further transgression depositional site of each unit has been changed their position landward with preservation of its horizontal allotment in the selected study areas.

At the period, when the sea level was $40 \mathrm{~m}$ below the present one, transgression started but in Soma coastal plain while the sea level was $30 \mathrm{~m}$ below the present sea level the shoreline was located near the present one along the Mat- 
sukawa bay. At the period of $-25 \mathrm{~m}$ sea level, the sea area expanded further westward in the central part and it reached to the place about $3 \mathrm{~km}$ inland ward from the present shoreline. At the following period of $-20 \mathrm{~m}$ sea level, the transgression sea water expanded further more trend to northward from the central part. While the sea level was $10 \mathrm{~m}$ below the present one, most of the lowland of Soma plain was submerged and transgressive sea water expanded and occupied all the lowland area, resulting; formed a big bay which reached about $10 \mathrm{~km}$ inland ward from the present shoreline in the northern part and about $5 \mathrm{~km}$ in the southern part of this plain. When the sea level rose about $5 \mathrm{~m}$ below the present level, it assumed that the landward transgression was terminated and shoreline began to recede against the continuing rise of sea level. Besides, in Haramachi coastal plain while the sea level was $10 \mathrm{~m}$ below the present level, most of the lowland of south part invaded by the Holocene transgressive sea water resulting, inundated almost all the valley area and made a bay condition. Henceforth, while the sea level rose about $+0.5 \mathrm{~m}$ it assumed that the landward transgression was ceased and shoreline began to recede against the continuing rise of sea level. Moreover, in Namie coastal plain, while the sea level was about $8 \mathrm{~m}$ below the present one, almost all the lowland invaded by transgressive water body and was submerged. At the time, transgressive sea water expanded and occupied all the lowland area resulting, formed a bay. When the sea level rose about 3 $\mathrm{m}$ below the present sea level it presumable that the landward transgression was ceased and shoreline began to recede against the continuing rise of sea level.

Back barrier sediments were deposited under brackish water to fresh water condition by wash over storm surges, inlet intrusion of marine sediments reworking by fluvial activities while the barrier was positioned and located on protruding sector of a coast during the mid to late Holocene period. Thus, back barrier region were developed as well as back marsh deposits were formed after termination of wash over and inlet intrusion of marine sediments while the barrier evolution was ceased.

Last of all, due to the geomorphic development of landforms and surface materials of the se- lected coastal lowlands, there are some differences. In spite of the same scale of rivers flowing, in the Haramachi and Namie coastal lowlands sandy and gravelly soil developed more than the Soma coastal lowland. Because, the river courses of the Soma plain carries gravel to the coast. Notwithstanding, according to erosion activity there are big differences among the selected study areas. Fukushima coasts in particular, the Haramachi and the Namie coast suffering from beach and coastal cliffs erosion from the ancient period that still going on. Regarding this, the Haramachi and Namie plain are rapidly retreated landward. Moreover, due to dominant littoral drift directing north the eroded sediments volume transported towards the north continuously and accelerate to developed further north coastal lowlands as well as developed the Soma coastal plain. Thus, the Holocene barrier is existed and is well shown in Soma coastal plain by its narrow width but due to severe erosion activity, the Holocene barriers in Haramachi and Namie plain have disappeared gradually.

By the very fact, the above-mentioned phenomena which have been described beforehand are the paleo-environments and geomorphic changes of the Fukushima coastal zone as well as the paleo-geography of the study areas.

\section{Dhananjay REGMI: A Geomorphic Study of Permafrost in the Nepal Himalaya. Hokkaido University, February 2006.}

Permafrost in Nepal has received very little scientific attention, despite the fact that Nepal is a country known for the Himalaya. Even the distribution of permafrost in Nepal has not been clarified yet. This study deals with the distribution of rock glaciers and permafrost in five high Himal areas of the Nepal Himalaya: Kangchenjunga, Khumbu, Langtang, Annapurna, and Sisne.

Permafrost is an invisible phenomenon and its presence is difficult to identify. Therefore, an indicator landform of rock glaciers was used for aerial photograph interpretation to identify the present distribution of permafrost in five areas. Field observations were also made in order to check the rock glaciers in three areas of Kangchenjunga, Khumbu, and Langtang. First, rock glaciers of periglacial-origin and those of glacial-origin were mapped; and then size, alti- 
tude, and aspect of each periglacial-origin rock glaciers were analyzed by GIS. The results show that: (1) High amount of precipitation in eastern Nepal leads to the development of glacier-origin rock glaciers; (2) the size of the rock glaciers tends to decrease from the east (Kangchenjunga) to the west (Sisne); (3) the mean altitude of rock glaciers decreases towards the west; and (4) the aspects of the rock glaciers are variable, but southerly directions are most common.

Intensive field surveys were carried out at three sites in Langtang Himal (Yala, Gangja La and Helambu) to examine the relationship between permafrost distribution and geomorphological arrangement. Altogether, 140 seismic surveys, 9 ground temperature profile measurements, and 48 BTS (Bottom Temperature of Snow) surveys were conducted. The results obtained from each method were then crosschecked to minimize potential errors. The combined results from the three methods show that (1) the altitudes of the lower limit of the permafrost lie at $4,740 \mathrm{~m}$ at Yala site, at $4,820 \mathrm{~m}$ at Gangja La site, and at $4,670 \mathrm{~m}$ at Helambu site; (2) permafrost occurs in areas adjacent to rockwalls and in moraine areas where the glaciers have been retreating rapidly; and (3) the permafrost areas lie within the horizontal distance of about $300 \mathrm{~m}$ from the base of the rockwalls, whereas they lie within the distance of about $700 \mathrm{~m}$ from the glacier termini.

The foregoing results on the relationship between the permafrost area and debris-accumulated areas suggest a possibility that the permafrost development is strongly related to the debris supply, such as rockfall. Rockfall activities and exposed bedrock thermal regime were monitored and evaluated at altitudes between 4,600 $\mathrm{m}$ and 6,000 $\mathrm{m}$ in Kangchenjunga Himal. Effective freeze-thaw cycles were first calculated from measured rockwall temperatures at different altitudes, and then, the exposed rockwall area was analyzed by GIS. The results show that: (1) the south-facing rockwalls experience frequent diurnal freeze-thaw cycles, while the north-facing rockwalls are characterized by seasonal freeze-thaw cycles; (2) the south-facing rockwalls have greater number and amount of rockfall than the north-facing rockwalls; and (3) the altitudinal belt responsible for the rockfall activities ranges from $5,400 \mathrm{~m}$ to $6,000 \mathrm{~m}$ on the south-facing rockwalls, and from $5,000 \mathrm{~m}$ to $5,600 \mathrm{~m}$ on the north-facing rockwalls.

Finally, factors responsible for deciding the size, altitude, and aspect of the rock glaciers in the Nepal Himalaya were discussed focusing mainly on the debris supply regimes from adjacent rockwalls. Summer precipitation water experiences freezing and thawing to expand cracks of the rockwall surface, so that more rockfall debris is produced; therefore, the concurrence of the effective freeze-thaw cycles and the large exposed rockwall area, especially of southerly directions, is considered as the major controlling factor for the development of the permafrost including rock glaciers.

\section{SAITO Motoko: "Geographical Knowledge" and American Female Missionaries in Meiji Era Japan. Ochanomizu University, March 2006.}

This dissertation is one application of feminist historiography of geography advocated by geographer Mona Domosh. It investigates the contributions of American female missionaries in Meiji Era Japan to the spread of "geographical knowledge."

Feminist historiography of geography argues that what women did for progress in geography must also be paid attention to in the process of reinterpreting the history of geography from being simply a history of one academic discipline to be more inclusive and more comprehensive.

The key word "geographical knowledge" in this dissertation has the following characteristics. It contrasts with "geography as a discipline." Geography as a discipline is produced and acknowledged by the people called geographers. On the other hand, geographical knowledge is disseminated widely to the public through daily experience and economic or cultural activities by not only geographers but also missionaries, explorers, travelers, etc. This dissertation clarifies how and what kind of "geographical knowledge" the female missionaries collected and spread.

In the late 19th century, middle-class white women in America organized women's foreign missionary societies in each denomination of the Protestant churches and sent many single women as missionaries to non-Christian coun- 
tries. Most of female missionaries coming to Japan graduated from female seminariesmiddle schools for women in 19th century America-and had had experience teaching. Female seminaries emphasized science, beginning with geography as the first scientific subject to learn. Emma Willard, a founder of one of the female seminaries, was especially interested in teaching geography. She presented model lectures at many schools using textbooks she herself had authored. Because the missionaries had learned geography as well as methods of teaching geography at female seminaries, their activities in collecting and spreading "geographical knowledge" were based on a mastery of geography. This dissertation takes the Woman's Foreign Missionary Society of the Methodist Episcopal Church as a case study and examines the literary and educational activities of its missionaries in Japan.

"Geographical knowledge" as collected by the female missionaries was sent in two directions. Knowledge about Japan was sent to America, on the one hand, while knowledge about foreign countries was transmitted to Japanese people, on the other hand. The former was achieved by means of missionaries' reports to the periodicals published by their sponsoring society. The latter was accomplished by world travel essays published in the magazine Tokiwa (i.e. "evergreen") started by the female missionaries in Yokohama and by teaching world geography at Jyogakko (i.e. "female middle schools") established by the female missionaries.

The "geographical knowledge" collected and spread by female missionaries has three distinguishing characteristics. The first characteristic is an emphasis on the observations of women and even children from various perspectives. This shows the originality of the women's foreign mission movement because this movement was carried out exclusively by women under the slogan "women's work for women" and because they did not ask for any help from the church, either practically or financially. The second characteristic is a deep knowledge of hygiene and botany. This reflects the culture shared by middle-class white women in Victorian America. The third characteristic is the detailed information about political condition, natural resources of Japan and so on. This indicates what kinds of knowledge the church needs for missionary works and how female missionaries were involved in gathering that knowledge.

Among these three characteristics, the first and the second derive from differences between the women's organization and the male dominated church. But the third shows the women's efforts to help the church. The three characteristics illustrated an ambivalence in the women's foreign mission movement, because their attitude to the church was both resistant and subordinate.

From the viewpoint of feminist historiography of geography, the literary and educational activities of the American female missionaries in Meiji Era Japan contributed to progress in geography because of the following three reasons. The first contribution was to spread precise "geographical knowledge" about the end of the Tokugawa and the beginning of the Meiji Eras. At that time, geography textbooks in America still taught the Tokugawa Shogunate was Japan's government even after the Meiji Restoration. The missionaries corrected those mistakes and sent accurate, up-to-date information. The second was to make both American and Japanese women aware of, and interested in, foreign countries. The missionaries' reports in the periodicals stimulated commercial women's magazines in America to carry articles about overseas subjects. Subsequently, this trend influenced the Japanese women's magazine published by the female missionaries. It ran world travel essays serially. This story explains that the female missionaries played a role as an agency in spreading "geographical knowledge" among women. The third was to promote geography education in the middle schools for women in Meiji Era Japan. Jogakko established by the female missionaries were modeled after female seminaries in America. It followed the idea of female seminaries that geography was the first scientific subject to learn and did so using Cornell's geography textbooks which had been used widely in America. Jogakko were the chief schools giving secondary education for women in early Meiji Era. So it can be said that female missionaries made a great contribution to geography education in Meiji Era Japan. 


\section{Sudesiqin: Geographical Study on Farming and Grazing in Inner Mongolia Autonomous Region of China. Tohoku University, March 2006.}

This study has examined changes and immanent issues of the agriculture and grazing in Inner Mongolia Autonomous Region located in inner land area of People's Republic of China since 1998, a year considered to have marked a new era for Chinese agriculture and grazing economy. The study is based on household level investigation into change and current state of agriculture and grazing in three counties .

First, we took a typical pastoral region, showlonchagan county located in central Inner Mongolia, and investigated "Grassland Division Use System" since 1998 and the change of the grassland use and changes in livestock farming management and grassland use from socio-economic gap between grazing farmers perspectives, especially in the use of grasslands. Due to the introduction of "Grassland Division Use System," high quality grasslands were distributed to individuals, and these lands were fenced for private management by private investors, while on the other hand, mountainous regions and hilly areas with vulnerable vegetation remained as shared land with lack of the management system, and became dilapidated. it was found that the grassland degradation started in the shared land first, then to the entire grassland including private lands.

Second, we took two farming villages in the Wu Chuan County, and discussed how new policies introduced in late 1990s influenced inland agricultural regions, and how they concomitantly changed farming in the region. In the mountainous $\mathrm{Hu}$ Tong $\mathrm{Zi}$ village, newly introduced farmland system with long term use right as well as "Returning Cultivated Land to Grass Land System" and "No Grazing Policy" put great effect. In the owned farmland, the gaps in the owned land created in farmland distribution expanded further due to the implementation of "Returning Cultivated Land to Grass Land System." These gaps largely rules production and living activities of farmers, and some of the farmers becoming poor. On the other hand, in $\mathrm{Wu} \mathrm{Fu} \mathrm{Hao} \mathrm{village}$ located in relatively flat land, the situation is different from $\mathrm{Hu}$ Tong $\mathrm{Zi}$ village as the Wu Fu Hao village was designated as the county agriculture promotion area. Due to the change in farmland policies since 1998, the land use rights were distributed to households depending on their sizes, and managerial area was fixed, but the number of migrants moving out of the village during this time period has increased, and then land use rights were loaned to farmers and their relatives who were motivated to manage the land. At the same time, young household members increasingly moved out of the village for job opportunities. We argued that it was positive that the farmers raised their managerial incentive, but that there would be more risks of damaging the environment through production of a particular crop and introduction of large size livestock. Thus there was need for environmentally protective agriculture to peacefully coexist with nature.

Finally, changes in and problems of farming and grazing in marginal area were examined based on fieldwork investigation into farmers and grazers in Si Zi Wang county located in northern part of Inner Mongolia along with the border as most marginal region for farming and grazing. In Wang $\mathrm{Fu}$ village, after 1998, potato and oilseed rape began to be exclusively produced as they were highly cashable. Moreover, dent corns were produced for livestock feed. In addition, due to the introduction of farmland and grassland division system and no grazing policy, this created a gap in the area of owned lands between households, but some farmers utilized their family network to cope with the situation, and through increased number of livestock grazing, they increased their income. In the northern marginal grazing region of $\mathrm{Si} \mathrm{Zi}$ Wang County, the grazing family was influenced by policy factor such as grassland division and no grazing policy as well as economic factors such as tourism. Each household utilizes available resources such as proximity to major roads, existence of family network, and establishment of financial route. However, we still have to point out that the actions taken to ease the burden on environment by the government do not seem to be effectively working. In other words, while the regulation on the land use is well established, there is no regulation for the number of livestock, and thus the subsidy for no grazing end up being merely used 
for feed purchase. There may be more issues pertaining to distribution routing for dairy products and disposal of excreta if more households begin to have large sized livestock. The subsidy for no grazing has limit until 2008. In order to effectively reduce the environmental burden, it is necessary to take measures while considering the diverse nature of the grazers.

However, since Inner Mongolia has a vast land with diverse natural and socio-economic circumstances, there are many differences in how farming and grazing are carried out in individual regions. Therefore, there may be a region with different characteristics from what we presented with three sample regions. More empirical research is required for eastern and western regions of Inner Mongolia so that more comparison can be made between regions and thus the universalities and differences can be found.

\section{SUGITO Nobuhiko: Recurrence Patterns of Coseismic Surface Deformation on Active Reverse Faults: Case Studies on the Sekidosan Fault and the Active Faults along the Western Margin of the Nagano Basin. Kyoto University, March 2006.}

Previous tectonic geomorphological studies on active reverse faults have mainly analyzed them in time scales of thousand years or longer. However, few studies have ever focused on individual coseismic surficial deformations and their recurrence patterns in the last several thousand years, except for the most recent surface ruptures after the 19th century. In this thesis, we reconstruct evolution processes of several-meters-high tectonic landforms caused by active reverse faults, which express the most recent one or several coseismic surficial deformations, mainly on the basis of large-scale-airphoto interpretation and field investigation, and then examine recurrence regularity and complexity of coseismic surface deformation, with attention to the previously proposed models such as the 'characteristic earthquake model'. For that, we selected two test fields: the Sekidosan fault and the active faults along the western margin of the Nagano basin. Several-meters-high fault/monoclinal scarps have been well preserved along the fault traces.

The Sekidosan fault is a southeast-dipping 33- km-long active thrust located along the southeastern margin of the Ouchigata Plain, central Japan, with a net slip rate of more than 0.69 $\mathrm{mm} / \mathrm{yr}$. After detailed mapping of fault-related landforms, we carried out 34 topographic profiling across the tectonic scarps. 15 profiles were interpreted to represent the vertical displacement associated with the most recent surfacefaulting event, which allowed us to tectonic geomorphologically reconstruct the vertical slip distribution during the most recent event along the middle and northeastern parts of the fault. In addition, the amounts of vertical displacement along other 10 profiles nearly equals to twice the amounts of vertical displacement during the most recent event. Based on those data, we propose that the slip amounts at individual sites were almost the same during the latest two events, which agrees with the characteristic earthquake model in terms of recurrence of slip amounts. We also obtained geologic evidences for Holocene surface-rupturing thrust-faulting events by trench excavation and drilling surveys at Mijiro, Hongo, and Nakagawa-Udono sites, and identified three events dated at BC2880 to $\mathrm{BC} 2030$, BC1740 to BC40, and after AD1100, as well as the amounts of vertical displacement during those individual events at the Mijiro and Nakagawa-Udono sites. The amount of vertical displacement estimated from the geologic data at Mijiro site is discordant with the tectonic geomorphologically reconstructed slip distribution. This is probably because no tectonic landform caused by just the latest event has been preserved around the site. On the other hand, the amount of vertical displacement estimated at Nakagawa-Udono site is well consistent with the slip distribution. Those results mean that the slip distribution reconstructed by tectonic geomorphological analysis would be appropriate to a certain extent and useful to understand recurrence patterns of coseismic surface deformation. Ruptured length during each event is not shown by this thesis.

The western margin of the Nagano basin, central Japan, is bounded by west-dipping active reverse faults that extend for about $58 \mathrm{~km}$, with a vertical slip rate of approximately $2.0 \mathrm{~mm} / \mathrm{yr}$. Previous studies have suggested that the whole segments of the faults ruptured during the 1847 
Zenkoji earthquake. We applied to these faults the strategy same as for the Sekidosan fault, in addition to compilation of historical documents reporting surface ruptures of the Zenkoji earthquake. Based on detailed description of tectonic landforms, we conducted 17 lines of topographic profiling at five sites, three of which are located on the northern segment, one located on the central segment, and the other one located on the southern segment. Those tectonic geomorphological data indicate that the slip amounts at individual sites along all the segments were almost the same during the latest and penultimate surface faulting. We detected Holocene surfacerupturing reverse-faulting events by trench excavation and drilling surveys at Kusama and Komatsubara-Dannohara sites, including the 1847 event at both sites. At Komatsubara-Dannohara site, we were able to observe an east-vergent active wedge-thrust structure located basin-ward 10 to $15 \mathrm{~m}$ apart from the basal part of the eastfacing fault scarp. This is a valuable field example of active wedge thrust structures. Considering all the previous and newly obtained data, timing of the penultimate event on the northern to central segment and southern segment is estimated as AD690 to AD1160 and BC350 to AD1640, respectively. Consequently, we suggest that the recurrence pattern of the latest two surface faulting on these faults is well explained by the characteristic earthquake model or cascade model.

TAKANO Seiji: Functions and Development of the Railroad Station Area in the Inner City. The Tokyo University, September 2005.

The purpose of this study is to clarify the present status of the railroad station area and the old commercial core of Japanese cities and to portray the process of urban development projects there. It will be a help for considering the meaning of those areas in future transformation of the central part of city.

First, a complete survey of the cities above middle size in the whole country was conducted in order to clarify the changing central part of Japanese city quantitatively. It revealed that the center of city's commerce is moving from the old commercial core to the railroad station area in many cities. In addition, as the projects of "town planning on railroad station" become popular in late years, development of the railroad station area progressed. Since many of those projects tend to be accompanied by the establishment of a station passageway across station yard, the accessibility was improved in the back area of station which has been separated from the center of city by the "barrier effects of railroad." In conclusion, highly developed urban land use becomes widespread in the railroad station area.

When it comes to the development projects or the opening of large-scale retail stores, various political factors are involved. For the understanding of this situation, detailed investigation was conducted in Hachioji City, Tokyo as a sample study in the latter half of the paper. In Hachioji City, the influential people of the old commercial core which was historically formed along Koshu Road keep focusing their interests mostly on the reactivation of the declining old commercial core, their home town. That also ends up with ignorance of and interference with the development in the railroad station area, their strong competitor. Since Hachioji City has an old history, those influential people have occupied the nucleus of major business associations of the city including the Chamber of Commerce and Industry for a long time. The Chamber of Commerce and Industry can conduct surveys and make proposals for the municipal politics of commerce that is an official right assured by Japanese law system. Those influential people have tried to secure their own profits through those organizations, and performed big influence over municipal politics. Those evidences tell us that the development in the railroad station area is under the influence of reactivation of old commercial core.

The projects of "town planning on railroad station" also became clear through this study. Those projects are held with a focus on the railroad station, which is an important public facility in a city as well as a privately owned space by a railroad company. While the city seeks to modernize its railroad station area, the railroad company promotes station-related projects only in a range where those projects match their policies and interests. Negotiations between the city and the railroad company dominate the course of transformation of the railroad station area. There are 
station-related issues where the existing legal system cannot coordinate policies and interests between the city and the railroad company. This situation accelerates disputes between them and also time and energy necessary for the projects.

In conclusion, the railroad station area plays an important part in transformation of the central part of Japanese cities. Its academic understanding would be more necessary and better political and legal better solutions concerning urban development projects in the central part of city are expected.

\section{TAKAYANAGI Nagatada: Global Trans- formation of Spatial Structure in Agro-food Systems: Focusing on the Sector of Fruit and Vegetables. Tokyo University of Agriculture, October 2005.}

Globalization would put feeble Japanese agriculture in the crisis of collapse in the near future. In Japan, arable acreage has decreased; the labor force of primary industry fell down below 5 percent; agriculture accounts for less than only 2 percent of GDP. Japan has imported a massive volume of agricultural products and foods since the 1960 s, thus causing low self-sufficiency ratio in Japan's food supply. Needless to say, westernized Japanese dietary pattern, which means the consumption of meat and oil has increased, also contributed to this decline. The bottom line is, however, the increasing volume of low-price imports leads to shrinking restructure for producing areas, each of which consists of local farms, an agricultural cooperative and a local government, further thereby multiplying imported agricultural products.

The term of globalization can be defined as integrating process to the single regime in the world. This regime includes not only international trade agreements, but also trade practices or standardization of food products. The global world, however, consists of diverse regions in terms of physical environment, cultural milieu, and social setting. Although the mobility of products, labor force, and capital, has been heightened in the globe, national borders are still in force. Globalization provokes conflicts, disagreements, or contradictions among nation states, because each region, which is intrinsically heterogeneous, is relentlessly put in the surge of inte- gration. Accordingly, globalization can transform the spatial structure of agro-food systems on the scale of global, national, and local.

The purposes of this study to clarify how the spatial structure of agro-food systems is transformed by the globalization and to explore how local producing area should cope with the globalization in the view of agricultural geography and agricultural economics. This study focuses on the sector of fruit and vegetables, because this sector nowadays is the most important in the global agricultural trade in value.

Agricultural geographers in Japan have studied generally based on the regional approach despite many criticized that they only described indigenous characteristics of a particular region. On the other hand, location theory and spatial equilibrium analysis are premised on spatial homogeneity, because they attempt to establish pure theories. They disregard political powers or regimes in the actual society and do not consider whether the equilibrium situation is preferable in the globalized economy or not. Consequently, this study sublates both idiographic and nomothetic approaches to accomplish the purpose. In addition, this study discusses on the strategies of local producing areas for producers in Japan, agricultural cooperates, and local and national government to compete with imported foods.

The international trade of fruits and vegetables, which has rapidly expanded since recent decades ago, is the most significant part of the global agricultural trade. Although many geographers and sociologists describe the global structure of agro-food systems as the antagonism of the affluent North against the impoverished South, this framework is quite unsatisfactory for considering Japanese food issues, because international flows of FFV (fresh fruit and vegetables) have diverse patterns.

The globalization transformed spatial structures in the developed countries on national scale as well as in the developing countries. In the United States, industrialization of agriculture has progressed since the beginning of the last century, thereby forming monocultural belts such as the Corn Belt or the Cotton Belt to earn maximized profit. This tendency promoted geographical concentration of the producing crops partly influenced by the globalization. Higher risk 
of exporting business, for example shrinking demand affected by economic turmoil, and foreign trade policy that sometime hampers smoothly shipping throw small farms out of the business and annihilate small producing areas. On the other hand, regional disparity across Japan in both land productivity and labor productivity has increased, thus polarizing spatial stricture. The globalization is also one of the important factors in this transformation. In another words, international competition is different from intranational competition in transportation cost system and strategy of competitiveness.

Producing areas in harsh economic circumstances have two options for a countermeasure against a surge of low-price imported foods: brand marketing to sell continually their products at premium prices, bolstering of price competitiveness based on mass-production and massdistribution system.

Quality is the key element for the brand marketing. However, state-of-the-art technology or thorough screening inspection may not captivate urban consumers, so that they should take a differentiation strategy with remarkable features on their commodities. Although domestic convention is important to make a good impression for consumers, it cannot raise sales prices. More consumers recognize that the quality of a commodity is admirable, more demand of the commodity is boosted. Accordingly, public convention is particularly indispensable to establish brand images.

Localization is the important strategy against globalization. Numerous agricultural products and processed foods and beverages bear trademarks with a local place name in Japan. Emphasizing locality and tradition can enhance authenticity and reassurance of the commodity. As a result, growers or sellers can make immense profits from a hallmark with a place name that certifies the quality.

The difference in degree of localization in agro-food systems depends on history and cultural setting. While Europe officially protects geographical indications, the United States does not so much as have attention to the localized foods. Consequently, this dissension over food culture can provoke a conflict about trade practices.
Producing areas in Japan have to challenge global competition in the current third food regime. Brand marketing with high quality foods is suitable for niche commodities, because ordinary consumers cannot purchase exorbitant prime fruit or vegetables everyday. If all producing areas specialize in upscale brand marketing, volume sales products will not be grown inside Japan, causing lower self-sufficiency rate of foods. Accordingly, agglomeration of each developing package for a producing area does not necessarily contribute to an improvement of the self-sufficiency rate. In other words, what has to be noted is that even if individual economic agent rationally behaves on microscale, it will not result in most favorable effect as a whole. Cost reduction is also important method for producing areas in Japan as a consequence of this fallacy of composition. Division of labor in regional agriculture by group farming or cooperative works can optimally allocate human resource.

All these discussions make it clear that spatial structure in agro-food systems on world scale as well as on national scale has been transformed by the globalization. Although, many anti-globalization movements, for example slow food, community supported agriculture, direct selling, and regional circulation of organic waste, were mushroomed in recent years in the developed countries, various localizing activities will end up in temporal enthusiasm unless rural communities sustain economically viable conditions. Consequently, the two strategies, brand marketing and bolstering of price competitiveness, are not exclusive for each procuring area, yet it is important that combination of both made an assortment of producing areas in Japan as oppose to standardization and homogenization by the globalizing economy.

\section{TSUTSUI Yu: Studies on Management of a Shrine which Enshrines a Mountain God and Its Religious Area in Modern and Present Times: In the Case of Omonoimi Shrine in Yamagata Prefecture. Kyoto University, March 2006.}

Mt. Chokaisan $(2,236 \mathrm{~m})$ in Yamagata Prefecture is one of the most famous sacred mountains in the Tohoku area. Ascetics settled at the foot of the mountain in the Middle Ages and en- 
shrined it according to the Buddhist rites till the beginning of the Meiji era. In 1871, some Shinto priests who were public officials began to manage Omonoimi Shrine to worship Mt. Chokaisan, instead of ascetics by new laws. I tried to clarify how ascetics had been connected with the shrine since the Meiji era, how and why the shrine made an actual parishioner area around Mt.Chokaisan early in the Showa era and how regional differences of behavior of the shrine's believers were formed.

First, I discussed how ascetics were related with Omonoimi Shrine in the Meiji and Taisho times, through the analysis of archives kept in the shrine. In those times, guji, a line of chief priests of the shrine were national public officials, however most of the other low-class-priests were ascetics. Ascetics who did not become priests supported its management as owners of pilgrim's lodgings, guides in climbing Mt. Chokaisan and dedicators of sacred music or dancing. Since ascetics still continued to participate in management of the religious institution which enshrines Mt.Chokaisan, they had greater influence than a line of guji. So some guji had to change their management policies concerning human affairs or building into meeting ascetics' demands, so as not to incur their disobedience.

The second section showed how and why Omonoimi Shrine made an actual parishioner area around Mt.Chokaisan early in the Showa era. In 1933 a guji ordered some ascetic-priests to canvass influential people who lived in the area around Mt. Chokaisan for organizing believers' groups, called Chokai-ko which donated fixed money to the shrine regularly. Since ascetic-priests had visited its piedmont to propagate over three times a year, they could form 417 groups efficiently till 1945 . The reason why the shrine had to make an actual parishioner area around the mountain was to secure repairing expense. Then buildings of the shrine had many damaged parts, however it had no hope of getting enough money to repair them, because of a serious depression and legal restrictions.

In the third section, I investigated how regional differences of believers' behavior within Omonoimi religious area were formed through interviews with four kinds of religious groups: Okashira-ko, Chokai-ko, Tohai-ko and Kenkoku- ko. Within it, we can see four regional differences: (1) distributions of four kinds of religious groups, (2) naming of Tohai-ko, (3) Tohai-ko's destinations of mountain worship, (4) Tohai-ko's desires for mountain gods. As a result of my field survey, it is clear that these were formed by the following factors: (1) whether there were priests and mediums who had connections with ascetics, (2) the frequency of ascetics' propagation for believers, (3) conditions of landforms, and (4) the difference of the source of irrigation.

\section{WAKASA Sachi: Denudation Rates of Granite Landforms Estimated from Cosmogenic Radionuclide Analysis. University of Tsukuba, March 2006.}

Terrestrial in-situ produced cosmogenic nuclides have recently been used as tools for estimating denudation rates of landforms. Extremely small quantities of the nuclides are produced 'in situ' by interactions between secondary cosmic ray and target elements in minerals of terrestrial materials. Since there is no nuclide in target elements primarily, the extremely small quantities of nuclides are useful to estimate denudation rates. In the present study, denudation rates of two landforms are estimated using systematic nuclide production model.

First, a bedrock slope was chosen as a study site in Korea where the outer layers of rock separate in shells or spalls and slide down intermittently along with sheeting joints, i.e., peel away from the parent rock mass. This denudation process is called 'exfoliation' in the present study. The aim of the present study is to estimate the rate of intermittent exfoliation on a young surface based on a constructed model. Bedrock samples were collected along with the sheets and measured the concentrations of the nuclides to estimate the exfoliation rate of sheets. From the concentrations, it was not possible to calculate the steady-state erosion rate of the surface directly because each sheet was decimeters thick and was produced the nuclides by cosmic rays penetrating into the deeper sheets while they remain covered. Therefore, a model which indicates a relation between the geomorphological process and nuclide production at the study site were constructed including the effect of the thickness of each sheet. The model 
indicated that five episodic exfoliations occurred on the slope. From the model, durations between episodical exfoliation events were estimated. The duration lengthens with increasing the thickness of the sheets. The relation leads to the result that exfoliation of a sheet with a thickness of $5.6 \mathrm{~cm}$ occurs once per 1000 years. Moreover, integrated values of the durations indicate the minimum exposure ages of each sheet. The relation between the minimum exposure ages and the weathering rates from the Equotip hardness test reduces rapid early in the weathering and then decelerates.

Second, target of the analysis is paleo pediments. They are widely distributed in the western part of Korea. In the present study, paleo erosion rates of a pediment surface and a surface of a source area of gravel deposit were estimated using models of histories of the pediment surface and the surface of the gravel deposit based on the datable loess and depth profiles of the nuclide concentrations. Faces of the outcrops are classified into four layers from the surface: (1) alluvial deposit, (2) loess, (3) gravel layer, and (4) weathered granite (grus). Loess-paleosol sequences correlates with Marine Isotope Stages (MIS) 2 and 5. Grain size distributions for the gravel layer and angularity of the gravels indicate that the gravel layers have been transported as sheetflood. Four outcrops provided the samples for cosmogenic ${ }^{10} \mathrm{Be}$ and ${ }^{26} \mathrm{Al}$ analysis. Samples from the grus and gravel layer were collected from different depths to be measured concentrations of the nuclides. The concentration-depth profiles showed that one of the grus samples decrease exponentially with the depths and the other one of the gneiss gravel samples have no correlation with the depths. This suggested that the grus layer was unmoved (residual) and the gravel were mobile. A model assuming a simple exposure-burial scenario was constructed to interpret the concentrationdepth profiles of the nuclides of the grus samples. Calculation for two outcrops suggested the paleo erosion rates of $7-29 \mathrm{~mm} \mathrm{kyr}^{-1}$ at the paleo pediment surface. This rate is similar to the denudation rates of weathered bedrocks and soils, implying the paleo denudational processes gently washed the pediment surface. This coincides with the above suggestion that the paleo pedi- ment surface have been eroded by sheetflood. Then, the concentrations of gneiss gravels supplied from behind gneiss mountain are analyzed. Inherited nuclide concentrations produced before putting on the paleo pediment surface are included in the measured concentrations. From the inherited nuclide concentrations, paleo erosion rates of the gneiss mountain were calculated to be $17 \mathrm{~mm} \mathrm{kyr}^{-1}$ a little before or during last interglacial maximum and $23 \mathrm{~mm} \mathrm{kyr}^{-1}$ a little before or during post glacial period. A comparison between these erosion rates in the present study and that in earlier studies in other areas implies that the erosion processes on the surface of the gneiss mountain were avalanches and/or rockfalls.

\section{WAKATSUKI Tsuyoshi: Lithological Control on Soil Formation and Soil Slips in Weathering-limited Slopes Underlain by Granitic Rocks. University of Tsukuba, March 2006.}

On granitic mountains in humid regions, steep slopes where soil slips occur repeatedly due to heavy rainfall, generally have a thin weathered layer. The properties of the slope materials generally change abruptly at the boundary between the bedrock and the weathered layer. However only a few studies have investigated the effect of lithological properties on the structure and depth of the weathered layer. The purpose of the present study is to examine the influence of weathering characteristics controlled by the parent rock type, particularly mineral grain sizes and mineral compositions, on the structure of the weathered soil layers and on the density and the return period of soil slips in granitic mountains. Four kinds of granite mountains were selected: two study areas are underlain by coarse-grained granite (Gr) and fine-grained granitic gneiss (Gn) located in the suburbs of Seoul, Republic of Korea and the other two areas are underlain by felsic biotite granite (Gb) and mafic hornblende biotite granite (Ghb) located in Taga Mountains, Ibaraki Prefecture, Japan.

The weathered soil layers are classified into two types based on the relation between the depths of potential slip plane and weathering front. Weathering material at the potential slip plane has a $N c$-value (simplified dynamic cone 
penetrometer hardness) of 5 . Weathering material at the weathering front has a $V p$-value (seismic velocity for primary wave) of approximately $380 \mathrm{~m} / \mathrm{sec}$. The $\mathrm{Gr}$ and $\mathrm{Gb}$ slopes have the same depths of the potential slip plane of $0.7-0.9 \mathrm{~m}$ and the weathering front of $0.7-1.9 \mathrm{~m}$. On the other hand, the Gn and Ghb slopes have the depth of weathering front of $3.8-4.9 \mathrm{~m}$ located deeper than the potential slip plane of $0.8-1.9 \mathrm{~m}$. The former soil layer in $\mathrm{Gr}$ and Gb slopes is classified into Type $A$ and the latter soil layer in Gn and Ghb slopes into Type $B$.

The results of cone penetration testing imply that the Gr area has a larger density of soil-slips than the Gn area because a larger amount of slopes is unstable to the occurrence of soil slips in Gr area than in Gn area. Air-photograph interpretation shows that the Gb area has a density of soil slip scars 2.8 times larger than the Ghb area. These findings show that the density of soil-slip scars on slopes having the Type-A soil layer is larger than that for Type $B$. This is caused by the following two reasons:

1) The formation of the potential slip plane becomes faster on slopes underlain by coarsegrained bedrocks (Gr, Type A) than by finegrained bedrocks (Gn, Type $B$ ). This is due to that more restricted leaching of plagioclase produces soft grus easier at or above the potential slip plane in Gr-slopes than in Gn-slopes because of the smaller specific surface area of the minerals and the larger permeability arising from weathering of coarser grains of bedrock.

2) The rising of groundwater table toward slope surface during heavy rainfalls is easier on slopes underlain by felsic bedrocks (Gb, Type A) than by mafic bedrocks (Ghb, Type B). This is due to that the depth of the weathering front becomes shallower in felsic bedrocks (Type A) because of smaller amount of mafic minerals such as biotite with higher susceptibility to chemical weathering in bedrock. Thus, the depth of the soil layer with hard grus lying between the potential slip plane and weathering front becomes thinner in felsic bedrocks (Type A) than in mafic bedrocks (Type $B$ ). This difference in weathering characteristics results in smaller permeability of weathering material below the slip plane in felsic bedrocks (Type A). The smaller permeability restricts soil water to move to the weath- ering front, so that chemical weathering is prevented and consequently the lowering of the weathering front is difficult.

Above results lead to the conclusion that the lithology of bedrocks, especially grain size of minerals and mineral composition, strongly controls the soil-layer structure, the rate of soil formation and the density of soil slips on granitic mountains.

\section{YAMAGUCHI Satoshi: Geographies of Domestic Migration and the Urban Life of Migrants in Post-war Japan. Kwansei Gakuin University, October 2005.}

For several decades, various qualitative studies have been conducted on institutions and praxes in urban society and on migration. Using ethnographic details, this paper aims to describe some of the aspects of migration and migrants in post-war Japan. This paper consists of two parts.

The first part includes detailed explanations for the patterns of migration and of residence as well as the networks of fellow country people from peripheral prefectures, in post-war Japanese industrial cities. Following the introduction (chapter 1), the paper re-examines the notions and methodologies, for example, place, group and ethnicity (chapter 2). A certain place, for example, should be imagined as being connected with an area that has diverse realities held by each inhabitant, who has expanded his or her own personal networks internally and externally with respect to that place.

Chapter 3 provides an outline of the phenomenon that many people in Japan migrated from rural areas to industrial cities after World War II. Next, the problem of the former studies of associations of fellow country people is highlighted. This study employs methodological individualism and thick description in order to understand the people who have lived in urban settings and who are not always involved in existent personal networks with fellow country people.

Chapters 4 and 5 present case studies of two groups consist of members who migrated from small settlements-Eishi and Uchikawauchi, respectively-in Kagoshima Prefecture. Owing to chain migration, the inhabitants of Eishi are relatively concentrated in the residential area of Amagasaki City. However, it was not always pos- 
sible for these migrants to interact with fellow country people due to extremely hectic situations during Japan's high economic growth. Their urban lives had begun to show diversity with respect to social, political and religious attitudes.

Many members of Kansai Uchikawauchi Muginomekai live in Amagasaki City, and many of them are male. Since the labour market was divided by gender and the destinations of migrating female labour were more dispersed than those of males in this case, the female rates of participation were lower than the male rates of participation.

Every Kenjinkai, the association of people from the same prefecture, consists of members who did not know each other before the formation of the association. In chapter 6 , we show that Amagasaki Kochi Kenjinkai was established merely as a campaign club for a local election candidate who had migrated from Kochi Prefecture. The scope of his effort to organize people was just the reach of Amagasaki City as the constituency for election.

Chapters 7 and 8 are related to the people who migrated from Okinawa and lived in Hyogo Prefecture. The Okinawans were often discriminated against in the labour and housing markets because they were regarded as 'non-Japanese' before World War II and as 'foreigners' when Okinawa was ruled by the United States. However, cohesions based on the collective ethnic identity of 'Okinawa' have not always been confirmed in their various living practices. Since Okinawans were segmented with respect to various aspects, under harsh conditions, they were dependent on individual personal networks prior to ethnic cohesion.

This paper terms the political situations discussed in chapters 4, 6 and 7 as 'kenjinkai politics' or politics related to the associations of fellow country people (chapter 9). However, in urban areas, political parties such as the Komeito and the Japan Communist Party were in the ascendant at the same time as 'kenjinkai politics' and influenced it. Since many migrants lost their existing personal networks to some extent upon migration, this provided them the opportunity to become involved in various networks.

The second part of this paper is related to the so-called phenomenon of 'shudan shushoku', the administrative labour migration programme, as a national project that was continued in approximately the same period as Japan's high economic growth. Unlike the assumption made by the neoclassical economy, the labour market is always being created by the praxes of various subjects in the political and social contexts (chapter 10). The notion of 'shudan shushoku' is based on the following two aspects: (1) making efforts to integrate the local labour market of young jobseekers into a national labour market and (2) making arrangements for 'shushoku ressha', a special train for young jobseekers. Both these attempts help to overcome the spatial barrier in the labour market.

It is believed that 'shudan shushoku' was established because of the special train from Aomori Prefecture to Tokyo in 1954. However, chapter 11 shows that (1) special trains for jobseekers had already been arranged since the $1930 \mathrm{~s}$, and (2) the strong effort made by local government officials to integrate local labour markets into a national market had been already (re)started since the early 1950s. Then, why is '1954' regarded as a myth? In 1953, the Tohoku area experienced a period of bad harvest. It was said that this increased the danger of people trafficking. So the government officials of Aomori Prefecture intervened in the labour market. If 'shudan shushoku', as an option, is better than trafficking, then it may be a mistake to consider such governmental intervention in the negative light.

When local labour markets were being integrated, the characteristics of inhabitants from each prefecture (kenmin-sei) were respected and sometimes (re)invented (chapter 12). Since there was a buyer's market in the 1950s, local government officials in rural areas had to show the good character of their own jobseekers to sell their redundant labour force competitively. Young jobseekers and workers might be disciplined and tortured by this (re)invented forced their 'good' characters.

The so-called national labour market is in fact neither natural nor stable. Okinawa was ruled by the United States from 1945 to 1972 , but the Japanese government was allowed to retain the residual sovereignty of Okinawa (chapter 13). The Ryukyu government-the civil service man- 
aged by the Okinawans-along with the Japanese government sought to negotiate with the United States Civil Administration of the Ryukyu Islands in order to integrate the local labour market of Okinawa with the Japanese labour market.

When the buyer's market turned into a seller's market in the $1960 \mathrm{~s}$, the peak period of economic growth, urban images of industrial cities became important. Jobseekers had a better selection of regions to migrate to and live in. Chapter 14 proves a series of urban image policy of Amagasaki City to resolve its notorious images of gang culture and the pollution problem.

\section{YOSHIDA Yusuke: Condition and Diversity of Handloom Production in Iran: Zilu (coarse cotton carpet), Cotton Cloth and Persian Carpet Production in Meybod Region, Yazd Province. Kansai University, March 2006.}

This is a study of the responses which different handicraft producers have made to the changing circumstances over the past two centuries in Iran. Up until recently, scholars of modern Iranian economic history have focused exclusively on the stagnation and decline of Iranian textile industries rather than their vitality. In contrast to this dominant narrative, I attempted to appreciate the dynamics of handicraft production from the nineteenth century to today.

This study consists of four parts.

In Part I, I attempted to explore the changing situations of Iranian handicrafts industry from the beginning of the nineteenth century to the first half of the twentieth century when Iran had been incorporated into capitalist world system. The first part of this study opens with a reexamination on the traditional thinking that most of the Iranian handicrafts had declined throughout the nineteenth century as a result of the influx of European goods. I uncovered the vitality and dynamism of domestic handwoven cloth production.

Secondly, by focusing the trends of cotton cloth and yarn imports from European countries, I explored influence of the imports upon the domestic handwoven cloth production. Thirdly, I explored the production of Persian carpets during the first half of the nineteenth century. Persian carpet production was limited within limited areas during this period.
Finally, by focusing the trends in the exports of Iranian handwoven cloth and Persian carpets, I revealed the structure of Iranian economy and trade during this period.

In Part II, I attempted to shed light on the locational change of handwoven cloth production and the relations between household industry and modern industry after the Second World War. Firstly, I briefly reviewed the history of Persian carpet production from the later nineteenth century to the Second World War.

Secondly, I examined the geographical diffusion of the household industry in Iran on the basis of national censuses of 1956, 1966, 1976 and 1986. There has been very regional difference of household industries in Iran, according to the difference of physical environment and condition of agricultural production. However, while regional specialization of household industry had disappeared throughout Iran, new geographical pattern of household industry of carpet production appeared till the mid-1970s. The monoculturalization in the diffusion process of carpet industry implied the disappearance of regionality of household industry in Iran.

Thirdly, I explored the beginning of modern textile industry in Yazd city on Plateau of Iran, which was one of the most important textile center in Iran. With growing of modern factories in this city in 1950s and 1960s, the number of handloom had rapidly decreased.

In Part III, relying on data gathered from field work, I treated handloom productions in the Meybod and Ardakan regions of Yazd Province. This area is one of the major cotton weaving centers in Iran. Main handloom productions of this region are (1) zilu (coarse cotton rug), (2) cotton cloth and (3) Persian carpet.

(1) Zilu production in Meybod has a long history which can be traced from the middle age. But until 1950, zilu weaving industry had only existed in Bashnighan which is a part of the center of Meybod region. Since the beginning of the 1950 s, master weavers of Bashnighan had begun to employ children as labour in the surrounding villages to raise the productive capacity. Eventually zilu workshops were widely distributed all over the Meybod region and approximately 1,500 or 2,000 weavers were weaving zilu at the beginning of 1970s. After this peak, zilu produc- 
tion steadily decreased from 1970 s as a result of competition with machine-made carpets. Nowadays, the number of zilu weaver is about 50-60. Interviews with weavers show that one of distinctive character of this industry is that now full-time weavers are rare. Second character is that the majority of zilu weavers have multiple occupations for survival such as day laborer in the construction sector or low-wage employment in the service sector.

(2) Now, few old women are weaving coarse cotton fabrics in the Meybod and Ardakan regions. But almost women of these regions had weaved various cotton cloths at home in days of old.

(3) Unlike other crafts, Persian carpet production has not a long history in Meybod, because handwoven carpet industry had flourished in the western region of Iran and cotton culture had prospered in the eastern region from ancient time. But in 1960s, carpet production technique was introduced into this region from some traditional centers (Nain, Kashan, Yazd, etc.) where have a long history of Persian carpet production. So we can trace the process of homogeneization of household industry through the rug making in the Meybod region after 1960s.

In the final part of this study, I discuss the characteristics and differences of these three handloom industry ( $z i l u$, cotton cloth and carpet) to reveal the complex relations between local community and craft industries. There are differences between these three cases. These cases illustrate how weavers are embedded in a communal context and how they depend on a local weaving community in complex ways. In particular, the cotton weaving is done by women at home is declining dramatically. Cotton weavers, however, have made every effort to adjust and adapt to the change of economic and social conditions. Recently, some weavers began to weave colorful handkerchief consist of polyester yarn. Most of the weaving methods and techniques had not changed, although weaving styles and materials kept evolving. In other words, the new designs and use of new materials are innovations. Therefore, we can distinguish local innovations which depend on a regional heritage in not only the growing phase but also downswing phase of handicraft production.

\section{ZHONG Chong: A Historical-Geographical Study of the Formation and Structure of Regional Communities in Southeastern China: Lineage and Community in Bei-jiang Basin. Kyoto University, March 2006.}

Since the 1980s, insights into communities in Southeastern China have been deepened predominantly in the realms of history, cultural anthropology and sociology. However, a long-term lack of historical-geographical studies addressing the issues has resulted in an inadequate understanding of the formation and structure of regional communities in this area.

This dissertation is divided into 3 sections: a macro-scale study of Southeastern China, a micro-scale study of the Bei-jiang (北江) Basin, and a meso-scale study of the Gu-mo (姑末) area. The micro-scale study is central to the dissertation. The abstracts of the 3 sections are as follows:

(1) This section discusses the historical-geographical properties of Southeastern China: spatiotemporal stability in the humanities regions of Southeastern China, the diversity of culture and environment, and widespread lineage organizations in regional communities.

(2) The Bei-jiang Basin is one of the red basins in Southeastern China. In this alluviumfloored basin, country villages have highly developed lineage organizations over many years. Based upon an analysis of genealogies and fieldwork, this section provides a chronological survey of the various aspects, formation and growth process of the lineages in the Basin.

The section addresses a current spatial aspect of various lineages in the basin. There are 3 proposed patterns of spatial distribution of lineage which are assumed to represent different developmental phases. Based on these 3 developmental phases of lineage and an examination of genealogical registers, it is arguable that most lineages came into existence from the 10th century to the 15th century. Their organizations became widespread and popularized at the end of the 15 th century.

This section also discusses the founders of lineages in their respective genealogies. That is to say, records of the founders in the genealogies need to be carefully examined under textual criticism, as the earliest compilers of genealogies 
lacked knowledge of ancient ancestors and had tendency to reconstruct the founders retrospectively.

(3) This section gives a historical-geographical survey of the existence and the growth process of the Gu-mo area. Historical sources of information about Gu-mo tribe in the proto-historic age, documentary records of the changes of administrative division in the historic age, and a modern dialects atlas, are mainly used. Finally, the spatiotemporal stability and other historicalgeographical properties of the regional communities in this area are proved in the section.

\section{ZHANG Gui-Min: A Geographical Study on Systematization of Agricultural Space in Okabe Town, Saitama Prefecture. Tokyo Metropolitan University, September 2005.}

This study aims to clarify the mechanism of formation of the vegetable producing area in Okabe Town of Saitama Prefecture and the conditions of its sustained development. As the study area, three settlements were selected; Hanzawa-shinden Kami, Naka and Shimo, in Okabe Town of Saitama Prefecture. Tracing back to the mid 1970s, when the main industry was converting from sericulture management to fresh vegetable production, I tried to clarify the formation process of vegetable producing area and its mechanism, and to consider the conditions for the formation of vegetable producing area and its sustained development, with emphasis on the analysis of the transition of management at the farm household level.

The conclusion is as follows. The decline of sericulture and the development of vegetable production in Okabe Town of Saitama Prefecture have quite close relationship with the change of socioeconomic environment surrounding the local community. And the improvement of agricultural management environment in this area has promoted the formation of vegetable producing area. At the level of farm household, internal farming conditions of each household had the strongest influence over the farmer's decision-making. Some of the most important internal farming conditions are: acreage of management farm; farm labor force, especially male farm workers; successors of agricultural management. Furthermore, when the successor got married and took part in the agricultural management, or when the head of household was alternated with younger generation, an opportunity to change the management policy is brought, and the introduction into a new management sector is encouraged.

The formation of vegetable producing area in Okabe Town has experienced three stages. First, in succeeding the introduction of broccoli production by an enterprising farmer, many farmers introduced broccoli one after another. Second, the individual farmers organized moderatelylinked groups of farmers to get more favorable conditions in the production and sales of agricultural products, to establish cooperative and complementary relationship between the farmers or settlements and to sustain the development. Third, they organized the Council for the Unified Shipment of Fruits and Vegetables within the jurisdiction of the Agricultural Cooperative. Thus, the individual vegetable producing farmers have been organized spatially, and the space for vegetable production has expanded from "point" (individual farm) to "plane" (vegetable producing area). 


\section{Information for Contributors}

Submission The Editors of the Geographical Review of Japan English Edition invite original articles, review articles, research notes, and book reviews. At least the first author must be a member or a subscriber. Manuscripts should be submitted with two extra copies. The Editors are responsible for deciding whether a paper is to be accepted, and the Association acquires full and exclusive copyright. Figures may be returned with prior approval from the Editors.

Manuscripts should be typed double spaced, on one side of white paper of A4 size. Their several parts (title page, abstract, text, acknowledgements, notes, references, tables and figures) should begin on separate sheets. An original article or a review article should not exceed 24 pages, a research note should not exceed 18 pages in print, including tables and figures. A book review should not exceed 2 pages. Excess pages may be considered only at the authors' cost. One page in print will not contain more than 4,500 letters.

Style Manuscripts should be written in English (American spelling). British spelling may be accepted according to the authors' background or study areas. Words must not be divided at the end of lines. Such abbreviations as e.g., i.e., etc. and et al. are not italicized. Japanese, Chinese, Russian etc. should be romanized; Japanese is romanized according to the Hepburn system, without macrons.

Title Page should include the full names of authors, and the names and addresses of their affiliations.

Abstract should not exceed 250 words. Key words should follow on a separate line.

Headings Section headings should be like Results and Discussion, and sub-section headings like Migration flows; the former is set in the center and the latter is flush at the left.

Notes should be numbered sequentially in the text and listed in a separate section after the text.

References should be listed alphabetically by surname. Titles of papers, books or periodicals in lan- guages other than English are given only in English if they have existing translations. Otherwise, they are given only in the original languages. English translations may be given in parentheses, but they are optional. In these cases, signs such as (J) or (JE) should be put at the end: $(J)$ means "in Japanese," and (JE) means "in Japanese, with an English summary." Examples are:

Dennis, R. 1989. Dismantling the barriers: Past and present in urban Britain. In Horizons in human geography, ed. D. Gregory and R. Walford, 194-216. London: Macmillan.

Johnston, R. J., Gregory, D., and Smith, D. M. eds. 1994. The dictionary of human geography. 3rd ed. Oxford: Blackwell Publishers.

Kraus, H. 1995. The new view of atmospheric fronts. Erdkunde 49: 81-105. (GE)

Morikawa H. 1990a. Regional urban systems in Japan. Human Geography 42: 97-117. (JE)

Morikawa H. 1990b. Toshika to toshi shisutemu. Tokyo: Taimeido. (J)

Okazaki S., and Sunamura T. 1994. Quantitative predictions for the position and height of berms. Geographical Review of Japan 67B: 101-116.

Examples of citations in the text are: (Dennis 1989; Johnston et al. 1994), (Kraus 1995: 101-102), (Morikawa 1990a, 1990b), (Okazaki and Sunamura 1994).

Tables and Figures should be numbered sequentially, e.g., Table 1, Figure 1. Only horizontal lines are used in the tables. Notes to each table are indicated by letters from the English alphabet (e.g., 2,500 $)$. Captions for figures should be typed on a separate sheet.

Proof Reading Only the first proof will be sent to the (first) author.

Reprints of articles can be purchased by the authors, but authors under 30 years of age can receive 100 copies free of charge. 